\title{
1 Isolation and Gene Flow in a Speciation Continuum in Newts
}

3 Maciej Pabijan ${ }^{\mathrm{a}, \mathrm{b}, *}$, Piotr Zieliński ${ }^{\mathrm{a}}$, Katarzyna Dudek ${ }^{\mathrm{a}}$, Michał Stuglik ${ }^{\mathrm{a}, \mathrm{c}}$, Wiesław Babik ${ }^{\mathrm{a} *}$

$4{ }^{a}$ Institute of Environmental Sciences, Jagiellonian University, ul. Gronostajowa 7, 30-387,

$5 \quad K r a k o ́ w, P o l a n d$ katarzyna2.dudek@uj.edu.pl, piotr.zielinski@uj.edu.pl

6 michal.stuglik@uj.edu.pl

$7 \quad$ bermanent address: Department of Comparative Anatomy, Institute of Zoology and Biomedical

8 Research, Jagiellonian University, ul. Gronostajowa 9, 30-387, Kraków, Poland

9 ' Scotland's Rural College, Integrative Animal Sciences, Easter Bush Campus, Midlothian EH25 9RG, Scotland, UK

$11 *$ Corresponding authors:

12 Maciej Pabijan, Department of Comparative Anatomy, Institute of Zoology and Biomedical

13 Research, Jagiellonian University, ul. Gronostajowa 9, 30-387, maciej.pabijan@uj.edu.pl

14 Wiesław Babik, Institute of Environmental Sciences, Jagiellonian University, ul. Gronostajowa 


\section{Abstract}

Because reproductive isolation often evolves gradually, differentiating lineages may retain the potential for genetic exchange for prolonged periods, providing an opportunity to quantify and understand the fundamental role of gene flow during speciation. Here we delimit taxa, reconstruct the phylogeny and infer gene flow in newts of the Lissotriton vulgaris species complex based on 74 nuclear markers sampled from 127 localities. We demonstrate that distinct lineages along the speciation continuum in newts exchange nontrivial amounts of genes, affecting their evolutionary trajectories. By integrating a wide array of methods, we delimit nine taxa and show that two principle factors have driven their genetic differentiation: time since the last common ancestor determining levels of shared ancestral polymorphism, and shifts in geographic distributions determining the extent of secondary contact. Postdivergence gene flow, indicative of evolutionary non-independence, has been most extensive between sister and non-sister taxa in Central Europe, while four southern European lineages have acquired the population genetic hallmarks of independent species (L. graecus, $L$. kosswigi, L. lantzi, L. schmidtleri). We obtained strong statistical support for widespread mtDNA introgression, previously suggested by discordance between mtDNA phylogeny and morphology. Our study suggests that long-term evolution in structured populations that may periodically exchange genes may be common: although some of these populations may become extinct or fuse, others will acquire complete reproductive isolation and will carry signatures of this complex history in their genomes.

Key Words: delimitation, reticulate evolution, taxonomy, amphibian 


\section{Introduction}

Speciation, regardless of the mechanisms or geographic settings in which it occurs, is typically a gradual process (Coyne and Orr, 2004). The consequences of this are manifold. First, we see various stages of speciation in nature which makes delimitation of separately evolving units challenging (Huang and Knowles, 2016; Wiens, 2007). Second, completion of speciation is by no means certain, other outcomes such as fusions or extinction are also likely (e.g. Rhymer and Simberloff, 1996; Rudman and Schluter, 2016). Gene flow may homogenize diverging gene pools (Petit and Excoffier, 2009; Slatkin, 1985), thereby limiting or even reversing differentiation. Third, it is unclear how much gene flow occurs between differentiating lineages, whether contact between such lineages causes massive introgression, and to what extent introgression is heterogeneous throughout the genome (Cruikshank and Hahn, 2014; Wolf and Ellegren, 2016).

Although theory provides some guidelines, the preceding questions are mostly empirical and need to be addressed by studying natural systems. Recent spectacular adaptive radiations may be less informative and more exceptional in this respect than commonly assumed, because extinction may not have yet had sufficient time to prune the more ephemeral products of divergent selection (Cutter and Gray, 2016). Therefore, careful analyses of taxa composed of metapopulation lineages at various stages of divergence (de Queiroz, 2007), which can be referred to as a speciation continuum, are needed. Because the necessary analyses lie at the interface of population genetics and phylogenetics, they require integration of tools from both fields. This is especially important for studies that explicitly incorporate gene flow into the equation, because population genetic approaches for inferring post-divergence gene flow are better developed than methods co-estimating phylogeny and gene flow (Sousa and Hey, 2013). Likewise, accounting for post-divergence gene flow is a major challenge for current species delimitation methods (Petit and Excoffier, 2009). 
European newts from the Lissotriton vulgaris group provide an empirical example of a speciation continuum influenced by genetic exchange between taxa. The Carpathian newt, $L$. montandoni (Boulenger, 1880) and the smooth newt, Lissotriton vulgaris (Linnaeus, 1758), have parapatric distributions in central Europe (Fig. 1a; Macgregor et al., 1990; Rafiński and Arntzen, 1987). The former is endemic to the Carpathian and easternmost Sudetes mountains, whereas the latter has a very large range in Central and Northern Europe, with a disjunct population surrounding the Greater Caucasus mountains (Fig. 1a). At the intraspecific level, L. montandoni is morphologically uniform across its range, reflected by only shallow genetic substructuring (Zieliński et al., 2014). In sharp contrast, L. vulgaris is morphologically differentiated into at least seven subspecies (Fig. 1a; Raxworthy, 1990). The smooth newt is found in a variety of habitats across the collective ranges of the subspecies (Bour et al., 2002; Bousbouras and Ioannidis, 1997; Schmidtler and Franzen, 2004; Skorinov et al., 2008) from deciduous woodlands, farmlands and pastures in European lowlands and mountainous regions, forest-steppe and taiga in western Siberia and Kazakhstan and pockets of humid habitat in otherwise dry woodland or scrub in southern Europe and Anatolia. Despite over a century of study, the status of the L. vulgaris subspecies is still controversial (Dubois and Raffaëlli, 2009; Schmidtler and Franzen, 2004; Speybroeck et al., 2010; Wielstra et al., 2015). The disagreement has been exacerbated by a general lack of concordance between morphologically assessed subspecific boundaries and spatial patterns of mtDNA variation (Fig. 1a, Fig. S1; Babik et al., 2005; Nadachowska and Babik, 2009; Pabijan et al., 2015). The traits used to distinguish the smooth newt subspecies pertain almost exclusively to male secondary sexual characters, which include the presence/absence and extent of dorsal crests and tail fins, toe flaps, tail filament, dorso-lateral ridges and pigmentation patterns (Raxworthy, 1990) that develop in aquatic habitats during the breeding season. Despite divergent courtship behavior (Pecio and Rafiński, 1985) that leads to strong but incomplete 
prezygotic sexual isolation between $L$. montandoni and $L$. vulgaris (Michalak and Rafiński, 1999; Michalak et al., 1997), these two species hybridize in and around the Carpathian mountains forming a bimodal hybrid zone (Babik and Rafiński, 2004; Babik et al., 2003; Kotlík and Zavadil, 1999). Hybridization has led to the replacement of the original mtDNA of L. montandoni by introgressed mtDNA of several $L$. vulgaris lineages (Babik et al., 2005; Zieliński et al., 2013). Moreover, genetic exchange among the different subspecies of $L$. vulgaris is suggested because five of the subspecific taxa do not form monophyletic mtDNA lineages (Fig. S1; Babik et al., 2005; Nadachowska and Babik, 2009; Pabijan et al., 2015). Areas of subspecies intergradation with morphological intermediates have been reported in central and southeastern Europe (e.g. Krizmanic et al., 1997; Schmidtler and Franzen, 2004;

Schmidtler and Schmidtler, 1983; Wielstra et al., 2015). These findings suggest that introgressive hybridization both between $L$. vulgaris and L. montandoni, and among the various subspecies of $L$. vulgaris, has the potential to blur boundaries among the different taxa.

Here, we provide a multi-faceted perspective on divergence and gene flow in the $L$. vulgaris complex. First, we postulate that morphologically diagnosable taxa within the complex constitute separately evolving metapopulation lineages (de Quieroz, 2007) and test this assertion using a clustering approach based on allele frequencies, a Bayesian multispecies coalescent delimitation method, and the genealogical sorting index. Second, we hypothesize that gene flow has blurred phylogenetic relationships and misled phylogeny reconstruction methods that do not take reticulation explicitly into account (Leaché et al., 2014; Solís-Lemus et al., 2016). Third, we predict that the extent of historical gene flow was most extensive among lineages inhabiting Central Europe, and use an Approximate Bayesian Computation framework to model gene flow between pairs of taxa. Finally, we apply the inferred nuclear phylogeny to statistically test the previously proposed hypothesis of extensive mtDNA 
introgression among morphologically diagnosable taxa. We demonstrate that isolation in space and time as well as post-divergence gene flow shape the genetic background of a set of metapopulations that have diverged in ecology and morphology including male epigamic traits.

\section{Material and Methods}

\subsection{Newt sampling}

Tissues (tail-tips) were sampled from 127 newt populations (i.e. breeding sites, Table S1 and Fig. 1b). Our sampling focused on capturing the genetic variation present in all morphologically defined taxa within the L. vulgaris group and all potential Pleistocene refugia (Babik et al., 2005; Nadachowska and Babik, 2009; Pabijan et al., 2015) and was therefore mostly limited to southeastern and central Europe. Because the results of the current study support the elevation of four taxa to the species level (see Discussion), we use this updated nomenclature throughout the text. One individual was sampled per locality. Altogether we analysed sequence data for 128 individuals (plus outgroup) which included 42 reported in Zieliński et al. (2016) and 87 sequenced for this study (Table S1).

\subsection{Laboratory procedures and datasets}

DNA from ethanol preserved tissues was extracted using either a standard phenol/chloroform technique or the Wizard Genomic DNA extraction kit (Promega). Amplification and sequencing of a panel of 74 nuclear, mostly 3'UTR markers, followed Zieliński et al. (2014). This procedure resulted in physically phased sequences of both haplotypes for most markers in most individuals. We used four different datasets for analyses (Table S2) i) dataset 1 with sequences of all 74 loci and all 128 individuals, ii) dataset 2 with sequences of all 74 loci but with 118 individuals (excluded 9 admixed individuals and one of two newts from locality Kapakli), iii) dataset 3 with sequences of all 128 individuals but 70 loci (excluded 4 loci with 
$>10 \%$ missing sequences), iv) dataset 4 consisting of SNPs extracted from 71 loci (excluded loci with $>10 \%$ missing data at nucleotide positions) and 120 individuals (including outgroup).

\subsection{Species delimitation}

Species delimitation was based on identifying distinct genetic groups from haplotype frequency data and validating the genetic clusters using multispecies coalescent-based and genealogical sorting methods.

Sequence alignments (dataset 1) were converted into input for STRUCTURE v.2.3.4 (Pritchard et al., 2000) by coding each haplotype as a unique integer in a custom Python script. If nucleotide sequences contained over 10 Ns or gaps, they were coded as missing data, if they had less than 10 Ns or gaps, then columns with missing data were removed from the alignment. This procedure ensured that haplotype identity was based on nucleotide differences between sequences (and not on e.g. indels or low-quality data) and provided a conservative estimate of the number of haplotypes per locus. STRUCTURE was run under the admixture model $(\alpha=1.0)$ with independent allele frequencies among populations $(\lambda=1.0)$ for $K$ from 1 to 12, iterated 10 times each. The Markov chain in each analysis was set to 1 million burnin steps; a further 2 million steps were used for parameter value estimation. STRUCTURE HARVESTER (Earl and vonHoldt, 2012) and CLUMPAK (Kopelman et al., 2015) were used process the STRUCTURE output and to evaluate the most probable number of clusters $(K)$ by examining $\log \operatorname{Pr}($ Data $)$.

We validated the genetic clusters identified by STRUCTURE by applying joint Bayesian species delimitation and species tree estimation using the program BPP v3.1 (Yang, 2015). This approach is based on the multispecies coalescent and compares different models of species delimitation and species phylogeny in a Bayesian framework, accounting for 
incomplete lineage sorting and gene tree-species tree conflict (Rannala and Yang, 2013; Yang and Rannala, 2010, 2014). Input alignments were constructed from dataset 2 by taking 10 sequences per marker for each of the 9 STRUCTURE-delimited operational taxonomic units (hereafter OTUs). This sampling strategy was based on the minimum number of sequences available per taxon (imposed by 5 specimens of L. v. meridionalis), with random subsampling of 10 sequences (without replacement) in all other taxa. Admixed individuals (as defined by STRUCTURE) were excluded from this analysis. We explored a wide variety of priors on the population size parameters $(\theta s)$ and divergence time at the root of the species tree $\left(\tau_{0}\right)$ (see Extended Methods in the Supplementary Material).

Next, we estimated gene trees in MrBayes 3.2 (Ronquist et al., 2012) and used them as input in Bayesian concordance analysis and an assessment of genealogical sorting (see below). We applied dataset 3; outgroups consisted of a single, randomly chosen haplotype per locus of a Lissotriton helveticus individual, or if unavailable due to lack of amplification, a single haplotype from either L. italicus (for 3 markers) or L. boscai (for 9 markers) from Zieliński et al. (2014). Nucleotide substitution models for each marker were determined in jModeltest 2.1.4 (Darriba et al., 2012) under the Bayesian information criterion. Due to the low phylogenetic information content of many of the markers, we did not partition the alignments into codon positions for those containing coding regions. We implemented two runs each with four chains for 3 million generations with trees and parameters sampled every 3000 generations. Convergence was assessed by comparing the - $\ln L$ values between runs and by examining parameter values for a subset of markers in Tracer (Rambaut and Drummond, 2007). We discarded half of recorded gene trees as burnin, combined runs and constructed an extended majority tree in MrBayes (allcompat command).

We quantified the genealogical distinctiveness of the OTUs by measuring exclusive ancestry across gene trees with the genealogical sorting index (gsi) of Cummings et al. 
(2008). This statistic measures the genealogical exclusivity of a grouping on a scale from 0 (random distribution of sequences among groups) to 1 (complete monophyly), and an ensemble statistic (egsi) is used to integrate across gene trees. Because the gsi is sensitive to disparity in group size, we randomly pruned leaves to a sample size of 10 (the minimum number of sequences available per group). Admixed individuals were also pruned from gene trees. We used the R implementation of the gsi (genealogicalSorting v.0.92). The null hypothesis that the degree of exclusive ancestry of each group was observed by chance was evaluated by $10^{6}$ permutations.

\subsection{Phylogeny estimation}

Our first phylogenetic approach involved using individuals as taxonomic units and concatenating the sequences of all loci. This procedure necessitates the selection of a single haplotype per individual per marker and becomes non-trivial if that individual is heterozygous at multiple loci, because the choice of which haplotype to concatenate into the matrix may influence both the topology and branch support of resultant trees (Weisrock et al., 2012). For each individual in dataset 2, we randomly merged haplotypes from each gene into two concatenated sequences (i.e., each individual was represented by two entries of 36, 918 bp consisting of 74 concatenated markers). We then pooled haplotypes for each candidate species and randomly selected half of the haplotypes from each group for analysis. We followed Weisrock et al. (2012) in conducting ten replicate analyses to assess consistency. We ran mixed-model phylogenetic analyses in MrBayes 3.2 on the CIPRES Science Gateway platform (Miller et al., 2010). We divided the alignments into 74 partitions corresponding to markers and assigned the optimal nucleotide substitution models to these partitions as previously determined by jModeltest. Each analysis consisted of two runs with 8 chains for 20 million generations with trees and parameters sampled every 5000 generations; burnin was set at 50\%. Convergence between runs was assessed by examining effective samples sizes and 
parameter values between runs in Tracer, and by comparing topologies in AWTY (Nylander et al., 2008).

The second phylogenetic method involved using BUCKy (Ané et al., 2007; Larget et al., 2010) to estimate levels of concordance in reconstructed topologies among the posterior distributions of gene trees generated in MrBayes. Because the number of unique tips per gene tree was prohibitive (see Extended Methods), we pruned the gene trees in the MrBayes posterior distributions by randomly selecting a single tip from each OTU using an R script from Weisrock et al. (2012), modified to accommodate our dataset and subsampling requirements. Admixed individuals were also pruned from gene trees. We tested a range of priors and parameter values for BUCKy (see Extended Methods). We pruned the original gene trees to 10 OTUs (9 candidate species plus outgroup) and repeated the subsampling and pruning routine 50 times, using BUCKy to calculate the primary concordance trees for each replicate. We measured clade support by calculating the mean $( \pm S D)$ sample-wide concordance factors for clades across all 50 replicates. We also measured clade support by computing the frequency with which each clade was recovered over all replicates.

\section{We constructed a maximum likelihood tree using TreeMix 1.12 (Pickrell and} Pritchard, 2012) which uses a covariance matrix based on allele frequencies of SNPs to infer the evolutionary relationships among pre-specified populations. The algorithm then identifies populations more closely related than predicted by the phylogeny and adds a "migration edge” between them, representing the direction and magnitude of gene flow (Pickrell and Pritchard, 2012). We used the nine OTUs and an outgroup as populations. Note that allele frequencies for our outgroup "population” were based on two gene copies because only one outgroup individual was sequenced per marker (see single gene analyses above). We extracted and sorted biallelic SNPs at each of the 74 markers according to minor allele frequency (MAF). Five SNPs with the highest MAF, i.e. most informative at the level of the entire 
dataset, were retrieved per marker, under the condition that they contained $<10 \%$ missing data at a nucleotide position; these positions were then converted to TreeMix format using a custom Python script. A total of 71 out of 74 markers met our criteria, resulting in a matrix of 355 SNPs (dataset 4). TreeMix was invoked with -k 5 to account for linkage disequilibrium for SNPs from the same marker. In consecutive analyses, we added from one to three migration edges to allow for gene flow in the tree. We also ran TreeMix with an alternative dataset using only 1 SNP per marker with the highest MAF.

\subsection{Gene flow among OTUs}

We first summarized the pattern of shared variation in our dataset by counting the numbers of shared haplotypes between OTUs in a custom Python script using dataset 2. We also used this dataset to calculate $d_{\mathrm{xy}}$ values among the newt OTUs in DnaSP v5 (Librado and Rozas, 2009).

We estimated gene flow between all pairs of OTUs (36 pairwise comparisons) in an Approximate Bayesian Computation (ABC) framework. We followed Zieliński et al. (2016) in removing all fully coding markers from analyses, excluding all missing data by removing loci or individuals in pairwise comparisons and excluding all admixed individuals; final datasets included 60-66 loci with between 5 and 24 sequences per taxon (Table S3). The information present in the data was summarized for each pairwise comparison with a set of 9 summary statistics (Table S3 and Extended Methods).

We tested four simple scenarios of pairwise species divergence and the extent and timing of interspecific gene flow: i) a no gene flow (NGF) model in which an ancestral population splits into two at time $\mathrm{T}_{\mathrm{SPLIT}}$ with no genetic exchange between descendant populations, ii) an admixture (ADM) model in which a fraction of genes is moved instantaneously from one population to the other; this can occur once independently in each direction at any time after divergence, iii) a constant gene flow (CGF) model in which gene 
flow is continuous and bidirectional between descendent taxa after TsPLIT, and iv) a recent gene flow (RGF) model in which continuous and bidirectional gene flow between descendent taxa was constrained to have occurred in the last 200,000 years (approximately 50,000 newt generations).

Coalescent simulations were done in fastsimcoal2.01 (Excoffier et al., 2013), and the ABC analysis was conducted within the ABCtoolbox (Wegmann et al., 2010); detailed prior and parameter values are given in the Extended Methods. A total of $10^{6}$ datasets were simulated under each demographic model from which we retained $1 \%\left(10^{4}\right)$ best simulations and computed the marginal likelihood of the observed and retained datasets under the generalized linear model (Leuenberger and Wegmann, 2010). To control the type I error for multiple comparisons, we used a Bonferroni correction and removed models with the nominal $\mathrm{P}<0.0125$. The best fitting model was then selected via Bayes factors.

We estimated the power to distinguish between the four models within the ABC framework by randomly picking 1000 pseudo-observed datasets from all simulations generated for each model and checking how often the ABC procedure correctly predicted the true model (the one that produced the dataset). Each pseudo-observed dataset was treated as the observed data and used to calculate marginal densities of all compared models; Bayes factors were used to select the best model. Because identical prior distributions were used for all pairwise comparisons, we conducted a single power analysis using populations with the fewest sequences (L. kosswigi - L. v. meridionalis). This can be considered the minimum estimate as all other comparisons (with larger sample sizes) will have more power in distinguishing between models.

Next, we formally tested whether the sharing of mtDNA haplotypes among Lissotriton groups could be accounted for by ILS (incomplete lineage sorting) or is due to hybridization. 
We assumed that the partially resolved nuclear phylogeny based on the concordant signal from concatenated/BUCKy/TreeMix analyses (further referred to as the species tree) reflects true relationships among the evolutionary lineages within L. montandoni/L. vulgaris and followed the statistical approach of Joyce et al. (2011). If mtDNA similarities among evolutionary lineages result from ILS, then mtDNA sequences simulated within the true species tree should replicate the observed mtDNA data. If mtDNA introgression has occurred, sequences simulated on alternative species trees, assuming closest relationships between the lineages showing highest mtDNA similarity, should better reproduce the observed data.

Because the relationships between the evolutionary lineages have not been resolved completely, both tests were based on four lineages with relationships well-supported by nuclear data: i) N L. v. vulgaris, L. v. ampelensis, L. kosswigi and L. montandoni; ii) S L. v. vulgaris, L. v. meridionalis, L. schmidtleri and L. graecus (Fig. 2). For L. montandoni two scenarios were evaluated, allowing introgression from either L. v. ampelensis or $\mathrm{N} L . v$. vulgaris. For each evolutionary lineage we randomly sampled one sequence from each locality for which mtDNA sequences were available (Babik et al., 2005; Pabijan et al., 2015; Zieliński et al., 2013). These sequences were used to calculate parameters (times of divergence and mutation-scaled effective population sizes of extant and ancestral taxa) of competing species trees in BPP v3.1. A thousand gene trees were simulated for each species tree with MCcoal. Sequences were simulated along gene trees using SeqGen (Rambaut and Grass, 1997) assuming the HKA + gamma model of sequence evolution with parameter values estimated in MEGA6 (Tamura et al., 2013). For each scenario mean and minimum uncorrected (p) distances between evolutionary lineages were calculated for 1000 simulated datasets and compared to the observed distances to obtain $P$ values for individual comparisons. $P$ values from individual tests were combined using Fisher's method.

\subsection{Data archiving}


Input data and custom scripts used for data transformation and analysis are available in Dryad digital repository with doi:[to be submitted upon manuscript acceptance]. DNA sequence alignments for all markers were submitted to GenBank: accession nos. [to be submitted upon manuscript acceptance]. Additional analyses are provided as Supplementary Data.

\section{Results}

The largest dataset 1 contained 128 individuals and 74 loci with an average of $72.1 \pm 20.29$ haplotypes/locus (range 29-117) and $1.9 \pm 3.87 \%$ missing data per locus. Markers were of similar length (498.9 $\pm 6.79 \mathrm{bp}$ ) and highly polymorphic with an average of $91.8 \pm 34.56$ segregating sites per marker, one third of these (29.1 \pm 9.52) were singleton polymorphisms (Table S4).

\subsection{Species delimitation}

Bayesian clustering solutions at $K \leq 6$ had low probabilities. $\operatorname{Pr}(K)$ plateaued at $K=7$ (Fig. S2) and therefore we further only considered analyses at $K=7-12$ (60 analyses in total). Most of these 60 analyses contained clusters that grouped all individuals of a given subspecies or species together (Fig. 1B, Table S5). The top ten analyses with highest $\ln \mathrm{P}$ all contained $K=9$ groups with identical arrangements of individuals in clusters. Analyses with $K>9$ contained at least one cluster that was assigned zero or trivial fractions of the data, indicating that under high $K$ values, the number of meaningful clusters was lower than the assumed $K$. We thus inferred 9 clusters with high certainty (Fig. 1B, Table S5). Five of these clusters correspond to morphologically designated species or subspecies: L. montandoni, L. graecus, L. v. meridionalis, L. kosswigi and L. lantzi. The nominal subspecies was subdivided into two clusters that we designate North L. v. vulgaris (N L. v. vulgaris) and South L. v. vulgaris (S L. v. vulgaris), with the former living predominantly to the north and east of the Carpathian arc and the latter to the west and south of the Danube. The genetic cluster encompassing $L$. 
schmidtleri, a taxon described from western Anatolia that is morphologically similar to the nominal subspecies, was also found in the southeastern Balkans. The genetic cluster including L. v. ampelensis contained four individuals from eastern Slovakia, extreme western Ukraine and Romania classified as L. v. vulgaris according to morphology. Following Rosenberg et al. (2001), we consider that the frequency with which each taxon formed an exclusive cluster over all 60 analyses is a reliable measure of its support (Table S5). This ranged from 70\% in L. kosswigi to $88 \%$ in L. graecus and L. schmidtleri and considerably exceeded the frequency with which particular taxa clustered together or were split into two or more groups. Some evidence of additional substructure was found in South L. v. vulgaris and L. graecus (Fig. S3). Admixture was consistently detected in nine individuals (7.0\%; Fig. 1B, see Table S1 for estimated admixture proportions), five of which originated from the western part of the range of L. vulgaris (admixed N L. v. vulgaris/S L. v. vulgaris, morphologically classified as L. v. vulgaris), a single individual from northern Serbia (L. v. ampelensis/S L. v. vulgaris, morphological L. v. vulgaris), one from Kosovo (S L. v. vulgaris/L. graecus, morphologically undetermined), and two morphologically undetermined newts from the Romanian Carpathians composed of two ( $\mathrm{N}$ L. v. vulgaris/L. v. ampelensis) or three ( $\mathrm{N}$ L. v. vulgaris/L. $v$. ampelensis/L. montandoni) genetic clusters.

We conducted joint inference of species delimitation and phylogeny using BPP 3 with the nine OTUs defined in STRUCTURE. The posterior probabilities of each of these equaled 1.00 in all analyses under a wide range of priors and different starting trees (Table 1). All models in the 95\% credibility sets contained the nine OTUs. The multispecies coalescent model in BPP recovered a number of different species trees under the applied parameter settings (Table 1); their topologies and posterior probabilities varied depending on the prior specification, and to a limited extent, on seed number. Although the latter may suggest a lack 
of convergence, species trees with highest support were mostly congruent across analyses.

Notably, L. montandoni and L. v. ampelensis were consistently recovered as sister taxa.

We used the gene trees calculated in MrBayes to estimate the genealogical exclusivity of each candidate species. Typically, each genealogy in the post-burnin posteriors had a different topology. This was expected because there was limited phylogenetic information contained within each marker and many tips (257 including outgroup) in the trees.

Unsurprisingly, consensus gene trees calculated for each marker were mostly unresolved, and showed high levels of discordance (data not shown). Nonetheless, the majority of the genealogies showed a nonrandom clustering pattern for the delimited Lissotriton groups as indicated by the highly significant egsi (Table 2). We inferred high exclusivity for L. kosswigi and $L$. lantzi and with about $40 \%$ of genes monophyletic, and moderate egsi values for $L$. graecus, L. montandoni, L. schmidtleri and L. v. meridionalis. The values of egsi were relatively low but still highly significant for L. v. ampelensis, S L. v. vulgaris and N L. v. vulgaris.

\subsection{Phylogenetic results}

In concatenation analyses, we found that the individuals within OTUs always formed clades with posterior probabilities (PP) of 1.0, we therefore collapsed individuals into groups and show a consensus tree over all replicates (Fig. 2A) and separately for each of the 10 concatenation replicates (Fig. S4). The positions of some clades were consistent across all replicates and were always fully supported $(\mathrm{PP}=1.0)$. These included the basal placement of L. montandoni, the subsequent split of clade 1 composed of L. graecus and L. kosswigi, and the sister group relationship of L. v. meridionalis and S L. v. vulgaris. Moreover, the concatenated analyses invariably identified clade 2 composed of L. lantzi, L. schmidtleri, S L. v. vulgaris, $\mathrm{N}$ L. v. vulgaris, L. v. ampelensis and L. v. meridionalis. Our replicate analyses 
differed in the choice of sequences at heterozygous loci during the concatenation process; the results show that this influenced the branching patterns of the concatenated phylogenetic analyses by altering the positions of 4 taxa within clade 2 (L. lantzi, L. schmidtleri, N L. v. vulgaris and L.v. ampelensis). Nearly all alternative arrangements were strongly supported in one or more concatenation replicates (Fig. S4).

A consensus of the 50 replicate primary concordance trees from BUCKy (Fig. 2B) shows that all L. vulgaris taxa grouped together (to the exclusion of $L$. montandoni) across all replicates. The mean concordance factor represented by the mean number of genes supporting this clade was $20.5 \pm 2.2$ out of a total of 70 genes. Clades 1 and 2 as well as the sister group relationship between S L.v. vulgaris and L. v. meridionalis were relatively well-supported, although concordance factors were generally low (on average $<15$ genes), suggesting that more than one tree may equally well describe the history of these taxa. We examined this issue by extracting concordance factors from each replicate BUCKy analysis for clades with relatively high support (mostly encompassing those with two terminal taxa, Fig. S5). Primary histories were well-discernible in the cases of L. montandoni, L. v. meridionalis, S L. $v$. vulgaris, L. lantzi, L. graecus and L. kosswigi. However, between 3 and 6 primary histories could be discerned for $\mathrm{N}$ L. v. vulgaris, L. v. ampelensis and L. schmidtleri, shown by similar mean concordance factors and largely overlapping quartiles (Fig. S5).

The maximum likelihood topologies recovered by TreeMix based on 1 or 5 SNPs per marker (Fig. 2C) were very similar to the consensus topology of the concatenated analysis (Fig. 2A). After adding migration edges, we recovered gene flow between L. v. ampelensis and $L$. montandoni, followed by gene flow of lesser magnitude between $L$. graecus and $L$. schmidtleri and the ancestor of S L. v. vulgaris and L. v. meridionalis (Fig. 2D and Fig. S6). 
We found a gradient in divergence values $\left(d_{\mathrm{xy}}\right)$ among newt OTUs ranging between 1.141.59\% (Fig. 3, Table S6). Each pair of OTUs shared haplotypes at some markers (Fig. 3), although in many cases this amounted to less than $2 \%$ and may be indicative of retained ancestral variation. The highest proportions were shared between $\mathrm{N} L . v$. vulgaris and $L . v$. ampelensis (9.1\%), L. montandoni and two other lineages (7.5 and 6.7\% for $\mathrm{N} \mathrm{L.} \mathrm{v.} \mathrm{vulgaris-}$ L. montandoni and L. v. ampelensis-L. montandoni, respectively) and three pairs involving S L. v. vulgaris and neighboring clades L. v. ampelensis, $\mathrm{N} L . v$. vulgaris and L. v. meridionalis (5.2, 4.6 and 3.3\%, respectively). We note that all instances of relatively high levels of haplotype sharing were inferred for Central European taxa that at present occur parapatrically. In most pairwise comparisons of OTUs within the ABC framework at least one model could reproduce the observed data (Tables S7 and S8). The analyses had good power to discriminate between the four models (Table S8). Posterior probabilities for models varied considerably among pairwise taxa comparisons (Fig. 4A) with a clear predominance of the admixture (ADM) model and only 6 comparisons in which recent (in the last 200 kya) or continuous gene flow prevailed, all confined to currently parapatric, Central European lineages. However, in other cases episodes of gene flow in the ADM model were timed to have occurred deep in the past (e.g. modal values for posteriors $>1 \mathrm{Ma}$ ), making ADM and NGF equivalent in the sense of ruling out recent and constant gene flow (e.g. in L. kosswigi-L. v. meridionalis, L. kosswigi-L. graecus, L. kosswigi-L. lantzi, L. montandoni-L. lantzi, L. montandoni-S L. v. vulgaris; Table S9). In other pairwise comparisons modal values for admixture times in the ADM model were inferred to have occurred relatively recently, close to the upper limit of the prior (e.g. L. montandoni-L. v. ampelensis, N L. v. vulgaris-L. kosswigi), making the ADM and RGF models comparable. However, the posterior distributions for the admixture time parameters were in general very broad, indicating that data were not very informative in dating admixture events. 
Phylogenies estimated from mtDNA under the assumption of ILS substantially differed from trees estimated assuming mtDNA introgression (i.e. the topology was incongruent with the species tree based on nuclear data, Fig. 5). Under ILS entire trees and internal branches were both very short. Minimum mtDNA divergence between lineages readily distinguished between ILS and hybridization. For both L. montandoni and L. graecus, scenarios assuming hybridization fit the data well and were strongly preferred over ILS (Table 3). One of the two hybridization scenarios involving L. montandoni fit the data better than the other, although both hybridization scenarios had much better fit than ILS. Apparently the scenario assuming introgression between $\mathrm{N}$ L. v. vulgaris and L. montandoni received higher support because of more extensive mtDNA haplotype sharing between these two than between $L$. montandoni and L. v. ampelensis. Mean mtDNA divergence between lineages was not informative in distinguishing between ILS and hybridization as both scenarios generated mean divergence that was not significantly different from the observed values (data not shown).

\section{Discussion}

This study documents a series of lineages representing a continuum of genetic divergence with ample evidence for historical contact and gene flow between lineages. We demonstrate the importance of geographic conditions (allopatry vs. parapatry) and historical contingencies such as time since divergence and timing of secondary contact in determining the continuum of divergence that can be quantified in the present. Moreover, we show that a combination of population genetic and phylogenetic approaches is required to describe and measure this continuum. In the following sections we discuss our findings for Lissotriton newts, their more general implications and outline research areas where methodological advances are needed. 
All applied delimitation methods, based on allele frequencies, multispecies coalescent and genealogical concordance, robustly delimited nine evolutionary lineages. Some of these lineages correspond to described morphological subspecies, while others are morphologically cryptic (N L. v. vulgaris, S L. v. vulgaris) or include two distinct morphologies (L. v. ampelensis). This result is not an artifact of limited sampling under isolation by distance, because admixed individuals are rare and boundaries between lineages in well-sampled areas are sharp. The delimited entities are distinguishable in both allele frequency-based and genealogical frameworks, but are at various stages of divergence (Fig. 3). Substantial admixture between $\mathrm{N}$ L. v. vulgaris and S L. v. vulgaris in the postglacial expansion area in western Europe indicates that some lineages retain considerable potential for genetic exchange. We found evidence for recent gene flow between five other lineage pairs, all of which occur parapatrically in Central Europe (Figs 1 and 4b; see Zieliński et al., 2016, for a detailed assessment of genetic exchange between L. montandoni and two L. vulgaris lineages). Moreover, episodes of gene flow between lineages in the more distant past may have been commonplace, given the overall weak support for the divergence with no gene flow model in the ABC analyses (Fig. 4), two cases of confirmed old mtDNA introgression (Table 3), and several other instances of mtDNA paraphyly (Babik et al., 2005; Nadachowska and Babik, 2009; Pabijan et al., 2015). Thus, it is by no means certain that all delimited newt lineages will continue to evolve independently. The newt system is a good example of a broader phenomenon: as reproductive isolation progresses, the incipient species experience a prolonged phase of parapatric/allopatric structured populations which may episodically exchange genes. In some instances, secondary contact may lead to the fusion of non-sister lineages over parts of their collective range (e.g. $\mathrm{N} \mathrm{L.v.vulgaris} \mathrm{and} \mathrm{S}$ L. v. vulgaris in western Europe). This interpretation is in line with recent genetic and molecular studies of speciation showing that post-divergence gene flow is common, e.g. it was an important 
feature of hominin history (Pääbo, 2015), and sometimes occurs at high levels (e.g. Muir et al., 2012; Nevado et al., 2011; Osborne et al., 2016; Sun et al., 2012).

\subsection{Newt phylogeny and evolution of male nuptial morphology}

The species tree of the L. vulgaris group could not be fully resolved (Fig. 2A). Relationships that received high support included $L$. montandoni as the outgroup to all $L$. vulgaris taxa, $L$. graecus and L. kosswigi (clade 1 ) as the sister group to other L. vulgaris lineages (clade 2), and the sister group relationship between S L. v. vulgaris + L. v. meridionalis. Although the monophyly of clade 2 is supported, the relationships among OTUs within this group are uncertain. However, we acknowledge that only one (TreeMix) of the four applied phylogenetic methods specifically modelled gene flow among OTUs. Nonetheless, wellsupported nodes in the concatenation and concordance analyses were compatible with the topology of the maximum likelihood tree from TreeMix, suggesting that gene flow among OTUs did not overwhelm the phylogenetic signal over all parts of the tree. However, species tree estimation in BPP under the multispecies coalescent consistently recovered a sister group relationship between L. montandoni and L. v. ampelensis (Table 1). Likewise, analyses using *BEAST (Heled and Drummond, 2010), which experienced overall convergence issues, produced similar results (data not shown). Given the strong evidence for recent gene flow among these two taxa (Fig. 4; Zieliński et al., 2016), we consider this relationship as highly unlikely. Coalescent-based species tree methods are sensitive to violations of the assumption of no gene flow, particularly between non-sister taxa (Leaché et al., 2013; Solís-Lemus and Ané, 2016), and are thus unsuited to study the relationships within the L. vulgaris complex. Given the increasing number of studies reporting reticulate evolution, there is an urgent need for progress in methods co-estimating phylogeny and gene flow in multispecies and multilocus datasets; phylogenetic multilocus network methods (Solís-Lemus and Ané, 2016; Yu et al., 2013, 2014) appear promising in this respect. 

evolution in newts. The male nuptial morphology of L. montandoni consists of a smooth and low crest, prominent tail filament and dorso-lateral ridges. Similar male morphologies are also as divergence in female preference for larger male body size (Haerty et al., 2007; Secondi et al., 2010). Whatever the underlying cause(s), our species phylogeny shows that montandonilike male morphology was present in the ancestral $L$. vulgaris population, conserved in the $L$. graecus/L. kosswigi clade, and replaced by the derived morphology in the sister clade giving ampelensis and L. v. meridionalis (Raxworthy, 1990) could be interpreted as independent, partial reversions to the ancestral morphology due to convergent evolution. Alternatively, and possibly more likely given the evidence for substantial gene flow from neighboring taxa, these intermediate morphologies could be the result of an influx of genes underlying the derived morphology and dilution of montandoni-like ancestral traits. These two hypotheses could be tested with genome-wide data.

524 Recognizing the limitations of existing methodologies, we explored gene flow between pairs of taxa in a model-based framework using Approximate Bayesian Computation (ABC). This approach, although quite simple, has been effective in unraveling the process of gene flow in 
528 flow and provided quantitative measures of support for the various models. However, analyses modeling gene flow between two populations without incorporation of additional populations have been criticized because ignoring such "ghost” populations may affect parameter estimates or even model choice (Beerli, 2004; Eaton et al., 2015; Slatkin, 2005; Strasburg and Rieseberg, 2010). We note though that pairwise comparisons among all extant taxa may partially alleviate this issue. The availability of all pairwise comparisons allows the identification and reinterpretation of problematic cases, such as support for recent gene flow between allopatric taxa which have not likely been in recent contact, but which both may have exchanged genes with other populations. In our case, inferences were largely consistent with the geographic distributions of the lineages (parapatry vs. allopatry) and we accept them as working hypotheses. In general, given the current state of the field, the use of simple pairwise models in complexes of interbreeding species may be useful because they offer a feasible way of distinguishing among different scenarios of gene flow and building more complex, but still testable, hypotheses. In addition to model selection, $\mathrm{ABC}$ estimates demographic parameters which

543 facilitate the interpretation of evolutionary history along the speciation continuum. Estimates of long-term, coalescent effective population sizes $\left(\mathrm{N}_{\mathrm{e}}\right)$ for the Lissotriton lineages are quite large, ranging roughly between 80,000 and 800,000 (Table S9). Independent assessments place the divergence time of L. montandoni and L. vulgaris between 3.7 to 6.3 mya (Stuglik and Babik, 2016), while mtDNA lineages within L. vulgaris split in close succession during

548 the late Pliocene and early Pleistocene (Babik et al., 2005; Pabijan et al., 2015). This timeframe suggests that most Lissotriton lineages have not attained the $4 \mathrm{~N}_{\mathrm{e}}$ generations when roughly half of the loci in the genome achieve reciprocal monophyly (Hudson and Coyne, 2002; Degnan and Rosenberg, 2009), thus widespread incomplete lineage sorting (Table 2) and the presence of identical haplotypes amongst all lineage pairs are expected (Fig. 3). 
553

554

555

556

557

558

559

560

561

562

563

564

565

566

567

568

569

570

571

572

573

574

575

576

However, the lineages exchanging genes most extensively (L. v. ampelensis, $\mathrm{N}$ L. v. vulgaris, S L. v. vulgaris, L. v. meridionalis) also have the largest $\mathrm{N}_{\mathrm{e}}$ 's (Fig. 4B, Table S9). This suggests that post-divergence gene flow contributed to elevated $N_{e}$ estimates, although longterm population structure within lineages may also inflate $\mathrm{N}_{\mathrm{e}}$. We postulate that the existence of a transitional phase, in which differentiated lineages exchange genes, may explain or contribute to the large ancestral population sizes inferred by various methods (IM, ABC, PSMC) in many species (e.g. Duvaux et al., 2011; Nadachowska-Brzyska et al., 2015; Won et al., 2005).

\subsection{Introgression explains mtDNA paraphyly}

With a partially resolved phylogeny, we were able to test statistically for mtDNA introgression suggested previously (Babik et al., 2005; Nadachowska and Babik, 2009; Pabijan et al., 2015). We confirmed introgression in two of the most striking cases (from $\mathrm{N} L$. v. vulgaris into L. montandoni and S L. v. vulgaris into L. graecus), effectively explaining the discordance between mtDNA, nuclear genes and morphology, and attributing it to extensive recent and ancient mtDNA introgression. While there is evidence that it has been accompanied by introgression of nuclear genes in the case of L. montandoni, we do not have strong evidence of nuclear introgression into L. graecus. Better power to reconstruct the extent and timing of nuclear introgression would be obtained with a larger amount of data, particularly from longer genomic regions to explore information contained in haplotype spectra (Harris and Nielsen, 2013).

\subsection{Taxonomic implications}

We note that the application of a rigid taxonomy in which we appropriate scientific names to all nine genetically distinct lineages delimited herein would not fully capture the intricacies of the evolutionary history of Lissotriton newts. As stated previously (Wiens, 2007), the 
delimitation of species poses the problem of thresholding the continuous processes of speciation and lineage amalgamation. Although a number of authors have recognized some of the morphological L. vulgaris subspecies as full species (e.g. Dubois and Raffaëlli, 2009; Frost, 2016; Skorinov et al., 2014; Wielstra et al., 2015), these relegations were not based on new data but on inconclusive mtDNA variation, geographic range limits, and morphology. We delimited four distinct southern taxa for which our data strongly suggest species status: L. v. graecus as L. graecus (Wolterstorff, 1906 ), L. v. kosswigi as L. kosswigi (Freytag, 1955), L. v. lantzi as L. lantzi (Wolterstorff, 1914 ) and L. v. schmidtleri as L. schmidtleri (Raxworthy, 1988) L. v. [and not L. schmidtlerorum, see Dubois (2007) and Dubois and Raffaëlli (2009)]. We base this assertion on the concordant signals of divergence and independence from allele frequency- and genealogy-based delimitation methods, genealogical sorting, a nearly complete lack of hybrids in well-sampled areas and little evidence for genetic exchange in the recent past. Moreover, L. kosswigi and L. lantzi are allopatrically distributed (Skorinov et al., 2014; Wielstra et al., 2015), making gene exchange with other lineages improbable in the near future. More extensive sampling in Bulgaria and eastern Greece is needed to characterize the contact between L. schmidtleri and other smooth newt lineages. On the other hand, four central European L. vulgaris lineages are interconnected by nontrivial amounts of gene flow. These taxa show fusion following range expansion in the morphologically cryptic $\mathrm{N} L . v$. vulgaris and S L. v. vulgaris, extensive genetic exchange with neighboring lineages in L. v. ampelensis, and continuous gene flow since divergence between $L$. v. meridionalis and S L. v. vulgaris. These results suggest that we may be observing the loss of incipient divergence through hybridization in these taxa. 
600

601

602

603

604

605

606

607

608

609

610

611

612

613

614

615

616

617

We found that Lissotriton newts represent a continuum of genetic divergence with varying levels of shared genetic variation among taxon pairs. This pattern invokes long-term isolation and independent evolution in four southern smooth newt species, genetic exchange across parapatric borders for several taxa in Central Europe, and effective fusion of previously separated gene pools of two lineages in the post-glacial expansion areas of Western Europe. The profound discordance between taxonomic boundaries and mtDNA in Lissotriton is explained by extensive mtDNA introgression rather than by other processes. These features make the $L$. vulgaris species group a suitable system to examine the fission/fusion dynamics of the speciation continuum. The newt system is relevant because many species may have experienced such long-term structured populations. However, we also highlight that better methods, jointly modeling incomplete lineage sorting and gene flow, are needed to analyze such systems.

\section{Acknowledgements}

We thank Marcin Piwczyński and Ben Wielstra for insightful comments on the manuscript. Piotr Grodek, Marcin Liana and Krystyna Nadachowska-Brzyska offered invaluable help in the field. Pim Arntzen, Konstantinos Sotiropoulos and Ben Wielstra generously shared samples and locality information. The work was funded by the Polish National Science Centre (2012/04/A/NZ8/00662 to W.B) and the Jagiellonian University (DS/WBiNoZ/INoS/762/15). 


\section{References}

620

621

622

623

624

625

626

627

628

629

630

631

632

633

634

635

636

637

638

639

640

641

Ané, C., Larget, B., Baum, D.A., Smith, S.D., Rokas, A., 2007. Bayesian estimation of concordance among gene trees. Mol. Biol. Evol. 24, 412-426.

Babik, W., Rafiński, J., 2004. Relationship between morphometric and genetic variation in pure and hybrid populations of the smooth and Montandon's newt (Triturus vulgaris and T. montandoni). J. Zool. 262, 135-143.

Babik, W., Szymura, J.M., Rafiński, J., 2003. Nuclear markers, mitochondrial DNA and male secondary sexual traits variation in a newt hybrid zone (Triturus vulgaris $\times$ T. montandoni). Mol. Ecol. 12, 1913-1930.

Babik, W., Branicki, W., Crnobrnja-Isailović, J., Cogălniceanu, D., Sas, I., Olgun, K., Poyarkov, N.A., Garcia-París, M., Arntzen, J.W., 2005. Phylogeography of two European newt species—discordance between mtDNA and morphology. Mol. Ecol. 14, 2475-2491.

Beerli, P., 2004. Effect of unsampled populations on the estimation of population sizes and migration rates between sampled populations. Mol. Ecol. 13, 827-836.

Bour, R., Bringsøe, H., Vanderhaege, M., 2002. Triturus vulgaris (Linnaeus, 1758) at its southern limit: distribution on the Peloponnese, Greece, with range extensions from the Central and South Peloponnese. Alytes 20, 67-76.

Bousbouras, D., Ioannidis, Y., 1997. The distribution and habitat preferences of the amphibians of Prespa National Park, in: Crivelli, A.J., Catsadorakis, G. (Eds.), Lake Prespa, Northwestern Greece. A Unique Balkan Wetland. Springer, the Netherlands, pp. 127-133.

Coyne, J.A., Orr, H.A, 2004. Speciation. Sinauer Associates, Sunderland, MA.

Cruickshank, T.E., Hahn, M.W., 2014. Reanalysis suggests that genomic islands of speciation are due to reduced diversity, not reduced gene flow. Mol. Ecol. 23, 3133-3157.

Cummings, M.P., Neel, M.C., Shaw, K.L., 2008. A genealogical approach to quantifying 
lineage divergence. Evolution 62, 2411-2422.

Darriba, D., Taboada, G.L., Doallo, R., Posada, D. 2012. jModelTest 2: more models, new heuristics and parallel computing. Nat. Methods 9, 772-772.

Degnan, J.H., Rosenberg, N.A., 2009. Gene tree discordance, phylogenetic inference and the multispecies coalescent. Trends Ecol. Evol. 24, 332-340.

de Queiroz, K., 2007. Species concepts and species delimitation. Syst. Biol. 56, 879-886.

Dubois, A., 2007. Genitives of species and subspecies nomina derived from personal names should not be emended. Zootaxa 1550, 49-68.

Dubois, A., Raffaëlli, J., 2009. A new ergotaxonomy of the family Salamandridae Goldfuss, 1820 (Amphibia, Urodela). Alytes 26, 1-85.

Duvaux, L., Belkhir, K., Boulesteix, M., Boursot, P., 2011. Isolation and gene flow: inferring the speciation history of European house mice. Mol. Ecol. 20, 5248-5264.

Earl, D.A., vonHoldt, B.M., 2012. STRUCTURE HARVESTER: a website and program for visualizing STRUCTURE output and implementing the Evanno method. Conserv. Genet. Resour. 4, 359-361.

Eaton, D.A., Hipp, A.L., González-Rodríguez, A., Cavender-Bares, J, 2015. Historical introgression among the American live oaks and the comparative nature of tests for introgression. Evolution 69, 2587-2601.

Excoffier, L., Dupanloup, I., Huerta-Sánchez, E., Sousa, V.C., Foll, M., 2013. Robust demographic inference from genomic and SNP data. PLoS Genet. 9, e1003905.

Frost, D.R., 2016. Amphibian Species of the World 6.0, an Online reference. Available at http://research.amnh.org/vz/herpetology/amphibia. Accessed December 20, 2016.

Harris, K., Nielsen, R., 2013. Inferring demographic history from a spectrum of shared haplotype lengths. PLoS Genet. 9, e1003521.

Haerty, W., Gentilhomme, E., Secondi, J., 2007. Female preference for a male sexual trait 
uncorrelated with male body size in the palmate newt (Triturus helveticus). Behaviour 144, 797-814.

Heled, J., Drummond, A.J., 2010. Bayesian inference of species trees from multilocus data. Mol. Biol. Evol. 27, 570-580.

Huang, J-P., Knowles, L.L., 2016. The species versus subspecies conundrum: quantitative delimitation from integrating multiple data types within a single Bayesian approach in Hercules beetles. Syst. Biol. 65, 685-699.

Hudson, R.R., Coyne, J.A., 2002. Mathematical consequences of the genealogical species concept. Evolution 56, 1557-1565.

Joyce, D.A., Lunt, D.H., Genner, M.J., Turner, J.F., Bills, R., Seehausen, O., 2011. Repeated colonization and hybridization in Lake Malawi cichlids. Curr. Biol. 21, R108-R109.

Kotlík, P., Zavadil, V., 1999. Natural hybrids between the newts Triturus montandoni and T. vulgaris: morphological and allozyme data evidence of recombination between parental genomes. Folia Zool. 48, 211-218.

Kopelman, N.M., Mayzel, J., Jakobsson, M., Rosenberg, N.A., Mayrose, I., 2015. Clumpak: a program for identifying clustering modes and packaging population structure inferences across K. Mol. Ecol. Resour. 15, 1179-1191.

Krizmanic, I., Mesaroš, G., Džukic, G., Kalezic, M.L., 1997. Morphology of the smooth newt (Triturus vulgaris) in former Yugoslavia: taxonomical implications and distribution patterns. Acta Zool. Acad. Sci. H. 43, 345-357.

Larget, B., Kotha, S.K., Dewey, C.N., Ané, C., 2010. BUCKy: Gene tree / species tree reconciliation with the Bayesian concordance analysis. Bioinformatics 26, 2910-2911.

Leaché, A.D., Harris, R.B., Rannala, B., Yang, Z., 2014. The influence of gene flow on species tree estimation: a simulation study. Syst. Biol. 63, 17-30.

Leuenberger, C., Wegmann, D., 2010. Bayesian computation and model selection without 
likelihoods. Genetics 184, 243-252.

Librado, P., Rozas, J., 2009. DnaSP v5: A software for comprehensive analysis of DNA polymorphism data. Bioinformatics 25, 1451-1452.

Macgregor, H.C., Sessions, S.K., Arntzen, J.W., 1990 An integrative analysis of phylogenetic relationships among newts of the genus Triturus (family Salamandridae), using comparative biochemistry, cytogenetics and reproductive interactions. J. Evol. Biol. 3, 329-373.

Michalak, P., Rafiński, J., 1999. Sexual isolation between two newt species, Triturus vulgaris and T. montandoni (Amphibia, Urodela, Salamandridae). Biol. J. Linn. Soc. 67, 343-352.

Michalak, P., Grzesik, J., Rafiński, J., 1997. Tests for sexual incompatibility between two newt species, Triturus vulgaris and Triturus montandoni: no-choice mating design. Evolution 51, 2045-2050.

Miller, M.A., Pfeiffer, W., Schwartz, T., 2010. Creating the CIPRES Science Gateway for inference of large phylogenetic trees. Proc. Gate. Comp. Environ. Work, 1-8.

Muir, G., Dixon, C.J., Harper, A.L., Filatov, D.A., 2012. Dynamics of drift, gene flow, and selection during speciation in Silene. Evolution 66, 1447-1458.

Nadachowska, K., Babik, W., 2009 Divergence in the face of gene flow: the case of two newts (Amphibia: Salamandridae). Mol. Biol. Evol. 26, 829-841.

Nadachowska-Brzyska, K., Li, C., Smeds, L., Zhang, G., Ellegren, H., 2015. Temporal dynamics of avian populations during Pleistocene revealed by whole-genome sequences. Curr. Biol. 25, 1375-1380.

Nevado, B., Fazalova, V., Backeljau, T., Hanssens, M., Verheyen, E., 2011. Repeated unidirectional introgression of nuclear and mitochondrial DNA between four congeneric Tanganyikan cichlids. Mol. Biol. Evol. 28, 2253-2267.

Nylander, J.A., Wilgenbusch, J.C., Warren, D.L., Swofford, D.L., 2008. AWTY (are we there 
yet?): a system for graphical exploration of MCMC convergence in Bayesian phylogenetics. Bioinformatics 24, 581-583.

Osborne, O., Chapman, M., Nevado, B., Filatov, D., 2016. Maintenance of species boundaries despite ongoing gene flow in ragworts. Genome Biol. Evol. 8, 1038-1047.

Pabijan, M., Zieliński, P., Dudek, K., Chloupek, M., Sotiropoulos, K., Liana, M., Babik, W., 2015. The dissection of a Pleistocene refugium: phylogeography of the smooth newt, Lissotriton vulgaris, in the Balkans. J. Biogeogr. 42, 671-683.

Pääbo, S., 2015. The diverse origins of the human gene pool. Nat. Rev. Genet. 16, 313-314.

Pecio, A., Rafiński, J., 1985. Sexual behaviour of the Montandon's newt, Triturus montandoni (Boulenger)(Caudata: Salamandridae). Amphibia-Reptilia 6, 11-22.

Petit, R.J., Excoffier, L., 2009. Gene flow and species delimitation. Trends Ecol. Evol. 24, 386-393.

Pickrell, J.K., Pritchard, J.K., 2012. Inference of population splits and mixtures from genomewide allele frequency data. PLoS Genet. 8, e1002967.

Pritchard, J.K., Stephens, M., Donnelly, P., 2000. Inference of population structure using multilocus genotype data. Genetics 155, 945-959.

Rafiński, J., Arntzen, J.W., 1987. Biochemical systematics of the Old World newts, genus Triturus: allozyme data. Herpetologica 43, 446-457.

Rambaut, A., Drummond, A.J., 2007. Tracer v1. 5. http://tree.bio.ed.ac.uk/software/tracer Rambaut, A., Grass, N.C., 1997. Seq-Gen: an application for the Monte Carlo simulation of DNA sequence evolution along phylogenetic trees. Comput. Appl. Biosci. 13, 235-238.

Rannala, B., Yang, Z., 2013. Improved reversible jump algorithms for Bayesian species delimitation. Genetics 194, 245-253.

Raxworthy, C.J., 1990. A review of the smooth newt (Triturus vulgaris) subspecies, including an identification key. Herpetol. J. 1, 481-492. 
Rhymer, J.M., Simberloff, D., 1996. Extinction by hybridization and introgression. Annu. Rev. Ecol. Syst. 27, 83-109.

Ronquist, F., Teslenko, M., van der Mark, P., Ayres, D.L., Darling, A., Höhna, S., Larget, B., Liu, L., Suchard, M.A., Huelsenbeck, J.P., 2012. MrBayes 3.2: efficient Bayesian phylogenetic inference and model choice across a large model space. Syst. Biol. 61, 539_ 542.

Rosenberg, N.A., Burke, T., Elo, K., Feldman, M.W., Freidlin, P.J., Groenen, M.A.M., Hillel, J., Mäki-Tanila, A., Tixier-Boichard, M., Vignal, A., Wimmers, K., Weigend, S., 2001. Empirical evaluation of genetic clustering methods using multilocus genotypes from 20 chicken breeds. Genetics 159, 699-713.

Rudman, S.M., Schluter, D., 2016. Ecological impacts of reverse speciation in threespine stickleback. Curr. Biol. 26, 490-495.

Schmidtler, J.F., Franzen, M., 2004. Triturus vulgaris (Linnaeus, 1758)-Teichmolch, in: Grossenbacher, K., Thiesemeier, B. (Eds.), Handbuch der Reptilien und Amphibien Europas. Aula Verlag, Wiesbaden, Germany, pp. 847-967.

Schmidtler, J.J, Schmidtler, J.F., 1983. Verbreitung, Ökologie und unterartliche Gliederung von Triturus vulgaris in der adriatischen Küstengebieten (Amphibia, Salamandridae). Spixiana 6, 229-249.

Secondi, J., Haerty, W., Lodé, T., 2005. Female attraction to conspecific chemical cues in the palmate newt Triturus helveticus. Ethology 111, 726-735.

Secondi, J., Johanet, A., Pays, O., Cazimajou, F., Djalout, Z., Lemaire, C., 2010. Olfactory and visual species recognition in newts and their role in hybridization. Behaviour 147, $1693-1712$.

Secondi, J., Lepetz, V., Théry, M., 2012. Male attractiveness is influenced by UV wavelengths in a newt species but not in its close relative. PLoS One 7, e30391. 
Skorinov, D.V., Kuranova, V.N., Borkin, L.J., Litvinchuk, S., 2008. Distribution and conservation status of the Smooth Newt (Lissotriton vulgaris) in Western Siberia and Kazakhstan. Russian J. Herpetol. 15, 157-165.

Skorinov, D., Doronin, I., Kidov, A., Tuniev, B., Litvinchuk, S., 2014. Distribution and conservation status of the Caucasian newt, Lissotriton lantzi (Wolterstorff, 1914). Russian J. Herpetol. 21, 251-268.

Slatkin, M., 1985. Gene flow in natural populations. Annu. Rev. Ecol. Syst. 16, 393-430.

Slatkin, M., 2005. Seeing ghosts: the effect of unsampled populations on migration rates estimated for sampled populations. Mol. Ecol. 14, 67-73.

Solís-Lemus, C., Ané, C., 2016. Inferring phylogenetic networks with maximum pseudolikelihood under incomplete lineage sorting. PLoS Genet. 12, e1005896.

Solís-Lemus, C., Yang, M., Ané, C., 2016. Inconsistency of species-tree methods under gene flow. Syst. Biol. 65, 843-851.

Sousa, V., Hey, J., 2013. Understanding the origin of species with genome-scale data: modelling gene flow. Nat. Rev. Genet. 14, 404-414.

Speybroeck, J., Beukema, W., Crochet, P-A., 2010. A tentative species list of the European herpetofauna (Amphibia and Reptilia)-an update. Zootaxa 2492, 1-27.

Strasburg, J. L., Rieseberg, L.H., 2010. How robust are “isolation with migration” analyses to violations of the IM model? A simulation study. Mol. Biol. Evol. 27, 297-310.

Stuglik, M.T., Babik, W., 2016. Genomic heterogeneity of historical gene flow between two species of newts inferred from transcriptome data. Ecol. Evol. 6, 4513-4525.

Sun, Y., Corcoran, P., Menkis, A., Whittle, C.A., Andersson, S.G., Johannesson, H., 2012. Large-scale introgression shapes the evolution of the mating-type chromosomes of the filamentous ascomycete Neurospora tetrasperma. PLoS Genetics 8, e1002820.

Tamura, K., Stecher, G., Peterson, D., Filipski, A., Kumar, S., 2013. MEGA6: molecular 
evolutionary genetics analysis version 6.0. Mol. Biol. Evol. 30, 2725-2729.

795

796

797

798

799

800

801

802

803

804

805

806

807

808

809

810

811

812

813

814

815

816

817

818

Wegmann, D., Leuenberger, C., Neuenschwander, S., Excoffier, L., 2010. ABCtoolbox: a versatile toolkit for approximate Bayesian computations. BMC Bioinformatics 11, 116.

Wielstra, B., Bozkurt, E., Olgun, K., 2015. The distribution and taxonomy of Lissotriton newts in Turkey (Amphibia, Salamandridae). ZooKeys 484, 11-23.

Wiens, J.J., 2007. Species delimitation: new approaches for discovering diversity. Syst. Biol. $56,875-878$.

Weisrock, D.W., Smith, S.D., Chan, L.M., Biebouw, K., Kappeler, P.M., Yoder, A.D., 2012. Concatenation and concordance in the reconstruction of mouse lemur phylogeny: an empirical demonstration of the effect of allele sampling in phylogenetics. Mol. Biol. Evol. 29, 1615-1630.

Wolf, J.B.W., Ellegren, H., 2016. Making sense of genomic islands of differentiation in light of speciation. Nat. Rev. Genet. 18, 87-100.

Won, Y.J., Sivasundar, A., Wang, Y., Hey, J., 2005. On the origin of Lake Malawi cichlid species: a population genetic analysis of divergence. P. Natl. Acad. Sci-Biol. 102, 65816586.

Yang, Z., 2015. The BPP program for species tree estimation and species delimitation. Curr. Zool. 61, 854-865.

Yang, Z., Rannala, B., 2010. Bayesian species delimitation using multilocus sequence data. P. Natl. Acad. Sci-Biol. 107, 9264-9269.

Yang, Z., Rannala, B., 2014. Unguided species delimitation using DNA sequence data from multiple loci. Mol. Biol. Evol. 31, 3125-3135.

Yu, Y., Barnett, R.M., Nakhleh, L., 2013. Parsimonious inference of hybridization in the presence of incomplete lineage sorting. Syst. Biol. 62, 738-751.

Yu, Y., Dong, J., Liu, K.J., Nakhleh, L., 2014. Maximum likelihood inference of reticulate 
820 Zieliński, P., Nadachowska-Brzyska, K., Wielstra, B., Szkotak, R., Covaciu-Marcov, S.D.,

821 Cogălniceanu, D., Babik, W., 2013. No evidence for nuclear introgression despite

822 complete mtDNA replacement in the Carpathian newt (Lissotriton montandoni). Mol.

$823 \quad$ Ecol. 22, 1884-1903.

824 Zieliński, P., Stuglik, M.T., Dudek, K., Konczal, M., Babik, W., 2014. Development,

825 validation and high-throughput analysis of sequence markers in nonmodel species. Mol.

826 Ecol. Resour. 14, 352-360.

827 Zieliński, P., Nadachowska-Brzyska, K., Dudek, K., Babik, W., 2016. Divergence history of 828 the Carpathian and smooth newts modelled in space and time. Mol. Ecol. 25, 3912-3928. 
829 Table 1. Joint Bayesian species delimitation and species tree estimation in the Lissotriton

830 vulgaris species group using BPP. Rows show results for different analyses; letters denote

831 replicate runs differing only by seed number. Population size $(\theta)$ and divergence time $(\tau)$

832 priors encompass a wide range of demographic and divergence scenarios. Starting guide tree

833 topologies were random unless specified otherwise (see footnotes). $N$ species shows the

834 numbers of species and their posterior probabilities (PPs) in each analysis (PPs for each

835 species within analyses were always 1.00). $N$ trees denotes the number of trees in the 95\%

836 credibility set, and the last column shows the topology and posterior probability of the highest

837 ranked tree in the set. 
bioRxiv preprint doi: https://doi.org/10.1101/095877; this version posted June 28, 2017. The copyright holder for this preprint (which was not certified by peer review) is the author/funder, who has granted bioRxiv a license to display the preprint in perpetuity. It is magte available under aCC-BY-NC-ND 4.0 International license.

\begin{tabular}{|c|c|c|c|c|c|}
\hline Runs & $\Theta^{\mathbf{a}}$ & $\tau^{\mathrm{a}}$ & $\begin{array}{c}N \text { species } \\
\text { (PP) }\end{array}$ & $\begin{array}{c}N \\
\text { trees }\end{array}$ & best tree and pp of model (delimitation + tree) \\
\hline 1a & $\mathrm{G}(1,35)$ & $\mathrm{G}(2,500)$ & $9(1.00)$ & 7 & $\begin{array}{l}\text { (L. graecus, (L. lantzi, ((L. schmidtleri, L. kosswigi), ((S L. v. vulgaris, } \\
\text { L. v. meridionalis), (N L. v. vulgaris, (L. montandoni, L. v. } \\
\text { ampelensis)))))); } 0.70905\end{array}$ \\
\hline 1b & $\mathrm{G}(1,35)$ & $\mathrm{G}(2,500)$ & $9(1.00)$ & 4 & $\begin{array}{l}\text { (L. graecus, (L. lantzi, (L. kosswigi, ((S L. v. vulgaris, L. v. } \\
\text { meridionalis), (L. schmidtleri, (N L. v. vulgaris, (L. montandoni, L. v. } \\
\text { ampelensis))))))); } 0.83335\end{array}$ \\
\hline $2 a^{b}$ & $\mathrm{G}(1,35)$ & $\mathrm{G}(2,500)$ & $9(1.00)$ & 4 & $\begin{array}{l}\text { (L. graecus, (L. lantzi, (L. kosswigi, ((S L. v. vulgaris, L. v. } \\
\text { meridionalis), (L. schmidtleri, (N L. v. vulgaris, (L. montandoni, L. v. } \\
\text { ampelensis))))))); } 0.81770\end{array}$ \\
\hline $2 \mathbf{b}^{\mathbf{b}}$ & $\mathrm{G}(1,35)$ & $\mathrm{G}(2,500)$ & $9(1.00)$ & 2 & $\begin{array}{l}\text { (L. graecus, (L. lantzi, (L. kosswigi, ((S L. v. vulgaris, L. v. } \\
\text { meridionalis), (L. schmidtleri, (N L. v. vulgaris, (L. montandoni, L. v. } \\
\text { ampelensis))))))); } 0.88070\end{array}$ \\
\hline $3 a^{c}$ & $\mathrm{G}(1,35)$ & $\mathrm{G}(2,500)$ & $9(1.00)$ & 3 & $\begin{array}{l}\text { (L. graecus, (L. lantzi, (L. kosswigi, ((S L. v. vulgaris, L. v. } \\
\text { meridionalis), (L. schmidtleri, (N L. v. vulgaris, (L. montandoni, L. v. } \\
\text { ampelensis)))))); } 0.82170\end{array}$ \\
\hline $3 \mathbf{b}^{\mathbf{c}}$ & $\mathrm{G}(1,35)$ & $G(2,500)$ & $9(1.00)$ & 2 & $\begin{array}{l}\text { (L. graecus, (L. lantzi, (L. kosswigi, ((S L. v. vulgaris, L. v. } \\
\text { meridionalis), (L. schmidtleri, (N L. v. vulgaris, (L. montandoni, L. v. } \\
\text { ampelensis))))))); } 0.85825\end{array}$ \\
\hline $4 a^{d}$ & $\mathrm{G}(1,35)$ & $G(2,500)$ & $9(1.00)$ & 3 & $\begin{array}{l}\text { (L. graecus, (L. lantzi, (L. kosswigi, ((S L. v. vulgaris, L. v. } \\
\text { meridionalis), (L. schmidtleri, (N L. v. vulgaris, (L. montandoni, L. v. } \\
\text { ampelensis)))))); } 0.79815\end{array}$ \\
\hline $4 b^{d}$ & $G(1,35)$ & $G(2,500)$ & $9(1.00)$ & 38 & $\begin{array}{l}\text { (L. graecus, (L. lantzi, (L. kosswigi, ((S L. v. vulgaris, L. v. } \\
\text { meridionalis), (L. schmidtleri, (N L. v. vulgaris, (L. montandoni, L. v. } \\
\text { ampelensis)))))); } 0.43710\end{array}$ \\
\hline $5 a$ & $\mathrm{G}(1,10)$ & $\begin{array}{l}\mathrm{G}(2, \\
2000)\end{array}$ & $9(1.00)$ & 9 & $\begin{array}{l}\text { (L. graecus, (L. lantzi, (L. kosswigi, (L. v. meridionalis, (L. schmidtleri, } \\
((L . \text { montandoni, L. v. ampelensis), (N L. v. vulgaris, S L.v. } \\
\text { vulgaris))))))); } 0.33805\end{array}$ \\
\hline $5 \mathbf{b}$ & $\mathrm{G}(1,10)$ & $\begin{array}{l}\mathrm{G}(2, \\
2000)\end{array}$ & $9(1.00)$ & 5 & $\begin{array}{l}\text { (L. graecus, (L. lantzi, (L. kosswigi, ((S L. v. vulgaris, L. v. } \\
\text { meridionalis), (L. schmidtleri, (N L. v. vulgaris, (L. montandoni, L. v. } \\
\text { ampelensis))))))); } 0.71930\end{array}$ \\
\hline 6a & $G(2,2000)$ & $G(2,2000)$ & $9(1.00)$ & 50 & $\begin{array}{l}\text { (L. v. meridionalis, (((L. graecus, L. lantzi), (S L. v. vulgaris, }(L . \\
\text { montandoni, L. v. ampelensis))), (N L. v. vulgaris, (L. schmidtleri, } L \text {. } \\
\text { kosswigi })))) ; 0.13655\end{array}$ \\
\hline $6 \mathbf{b}$ & $G(2,2000)$ & $G(2,2000)$ & $9(1.00)$ & 45 & $\begin{array}{l}((\text { L. graecus, L. lantzi), ((L. schmidtleri, L. kosswigi), ((S L. v. vulgaris, } \\
\text { L. v. meridionalis), (N L. v. vulgaris, (L. montandoni, L. v. } \\
\text { ampelensis))))); } 0.12370\end{array}$ \\
\hline $7 a$ & $\mathrm{G}(1,10)$ & $\mathrm{G}(1,10)$ & $9(1.00)$ & 3 & $\begin{array}{l}\text { (L. graecus, (L. lantzi, (L. kosswigi, ((S L. v. vulgaris, L. v. } \\
\text { meridionalis), (L. schmidtleri, (N L. v. vulgaris, (L. montandoni, L. v. } \\
\text { ampelensis))))))); } 0.66405\end{array}$ \\
\hline $7 b$ & $\mathrm{G}(1,10)$ & $G(1,10)$ & $9(1.00)$ & 5 & $\begin{array}{l}\text { (L. graecus, (L. lantzi, ((L. schmidtleri, L. kosswigi), ((S L. v. vulgaris, } \\
\text { L. v. meridionalis), (N L. v. vulgaris, (L. montandoni, L. v. } \\
\text { ampelensis)))))); } 0.77125\end{array}$ \\
\hline $8 a$ & $\mathrm{G}(1,10)$ & $G(2,1000)$ & $9(1.00)$ & 3 & $\begin{array}{l}\text { (L. graecus, (L. lantzi, ((L. schmidtleri, L. kosswigi), ((S L. v. vulgaris, } \\
\text { L. v. meridionalis), (N L. v. vulgaris, (L. montandoni, L. v. } \\
\text { ampelensis)))))); } 0.80270\end{array}$ \\
\hline $8 b$ & $\mathrm{G}(1,10)$ & $G(2,1000)$ & $9(1.00)$ & 9 & $\begin{array}{l}\text { (L. graecus, (L. lantzi, (L. kosswigi, ((S L. v. vulgaris, L. v. } \\
\text { meridionalis), (L. schmidtleri, (N L. v. vulgaris, (L. montandoni, L. v. } \\
\text { ampelensis)))))); } 0.48025\end{array}$ \\
\hline
\end{tabular}

841 with shallow divergence; G(2,2000), G(2,2000): small populations with shallow divergence;

$842 \mathrm{G}(1,10), \mathrm{G}(1,10)$ : large populations with deep divergence; $G(1,10), G(2,1000)$ : large

843 populations with intermediate divergence

b - starting tree according to consensus phylogeny 
bioRxiv preprint doi: https://doi.org/10.1101/095877; this version posted June 28,2017 . The copyright holder for this preprint (which was not certified by peer review) is the author/funder, who has granted bioRxiv a license to display the preprint in perpetuity. It is maglo available under aCC-BY-NC-ND 4.0 International license. 
848 Table 2. Ensemble genealogical sorting index (egsi) for Lissotriton operational taxonomic

849 units (10 alleles per group) based on 70 gene trees. All of the P values for egsi are $<0.000001$.

850 The last column provides the number of gene trees in which a group reached complete

851 monophyly.

\begin{tabular}{lll}
\hline group & egsi & monophyly \\
\hline L. lantzi & 0.692 & 27 \\
\hline L. kosswigi & 0.679 & 30 \\
\hline L. graecus & 0.564 & 17 \\
\hline L. schmidtleri & 0.559 & 14 \\
\hline L. montandoni & 0.548 & 16 \\
\hline L. v. meridionalis & 0.497 & 7 \\
\hline L. v. ampelensis & 0.349 & 0 \\
\hline South L. v. vulgaris & 0.343 & 0 \\
\hline North L. v. vulgaris & 0.281 & 0 \\
\hline
\end{tabular}

852 
bioRxiv preprint doi: https://doi.org/10.1101/095877; this version posted June 28,2017 . The copyright holder for this preprint (which was not certified by peer review) is the author/funder, who has granted bioRxiv a license to display the preprint in perpetuity. It is maf 9 available under aCC-BY-NC-ND 4.0 International license.

Table 3. Evaluation of fit of mtDNA sequence data to scenarios of incomplete lineage sorting

854 (ILS) and hybridization (Hyb). Lva - L. v. ampelensis; Lg - L. graecus; Lk - L. kosswigi; Lvm

855 - L. v. meridionalis; Lm - L. montandoni; Ls - L. schmidtleri; NLvv - North L. v. vulgaris;

SLvv - South L. v. vulgaris

\begin{tabular}{|c|c|c|c|c|c|}
\hline Scenario & Pair of lineages & $\begin{array}{l}\text { Minimum } \\
\text { divergence - } \\
\text { Observed }\end{array}$ & $\begin{array}{l}\text { Minimum divergence - } \\
\text { Expected (median of } \\
1000 \text { simulations) }\end{array}$ & $\mathrm{P}$ & Interpretation \\
\hline \multicolumn{6}{|c|}{ mtDNA introgression into L. montandoni } \\
\hline ILS & $\begin{array}{l}L m-L v a \\
L m-\mathrm{N} L v v \\
L m-L k \\
L v a-\mathrm{N} L v v \\
L v a-L k \\
\text { N } L v v-L k \\
\text { Combined } \\
\text { (Fisher's method) }\end{array}$ & $\begin{array}{l}0.0020 \\
0.0000 \\
0.0384 \\
0.0020 \\
0.0207 \\
0.0374\end{array}$ & $\begin{array}{l}0.0010 \\
0.0020 \\
0.0020 \\
0.0010 \\
0.0020 \\
0.0030\end{array}$ & $\begin{array}{l}0.258 \\
0.294 \\
0.002 \\
0.220 \\
0.006 \\
0.002 \\
0.00002\end{array}$ & $\begin{array}{l}\mathrm{O}=\mathrm{E} \\
\mathrm{O}=\mathrm{E} \\
\mathrm{O}>\mathrm{E} \\
\mathrm{O}=\mathrm{E} \\
\mathrm{O}>\mathrm{E} \\
\mathrm{O}>\mathrm{E} \\
\text { data do not fit } \\
\text { scenario }\end{array}$ \\
\hline Hyb1 & $L m-L v a$ & 0.0020 & 0.0010 & 0.034 & \\
\hline$L m-L v a$ & $\begin{array}{l}L m-\mathrm{N} L v v \\
L m-L k \\
L v a-\mathrm{N} L v v \\
L v a-L k \\
\mathrm{~N} L v v-L k \\
\text { Combined } \\
\text { (Fisher's method) }\end{array}$ & $\begin{array}{l}0.0000 \\
0.0384 \\
0.0020 \\
0.0207 \\
0.0374\end{array}$ & $\begin{array}{l}0.0010 \\
0.0098 \\
0.0010 \\
0.0098 \\
0.0108\end{array}$ & $\begin{array}{l}0.500 \\
0.046 \\
0.242 \\
0.150 \\
0.066 \\
0.0095\end{array}$ & $\begin{array}{l}\mathrm{O}=\mathrm{E} \\
\mathrm{O}>\mathrm{E} \\
\mathrm{O}=\mathrm{E} \\
\mathrm{O}=\mathrm{E} \\
\mathrm{O}=\mathrm{E} \\
\text { data do not fit } \\
\text { scenario }\end{array}$ \\
\hline Hyb2 & $L m-L v a$ & 0.0020 & 0.0020 & 0.514 & $\mathrm{O}=\mathrm{E}$ \\
\hline$L m-\mathrm{N} L v v$ & $\begin{array}{l}L m-\mathrm{N} L v v \\
L m-L k \\
L v a-\mathrm{N} L v v \\
L v a-L k \\
\mathrm{~N} L v v-L k \\
\text { Combined } \\
\text { (Fisher's method) }\end{array}$ & $\begin{array}{l}0.0000 \\
0.0384 \\
0.0020 \\
0.0207 \\
0.0374\end{array}$ & $\begin{array}{l}0.0000 \\
0.0089 \\
0.0020 \\
0.0089 \\
0.0098\end{array}$ & $\begin{array}{l}0.318 \\
0.040 \\
0.824 \\
0.110 \\
0.056 \\
0.0561\end{array}$ & $\begin{array}{l}\mathrm{O}=\mathrm{E} \\
\mathrm{O}>\mathrm{E} \\
\mathrm{O}=\mathrm{E} \\
\mathrm{O}=\mathrm{E} \\
\mathrm{O}=\mathrm{E} \\
\text { data fit } \\
\text { scenario }\end{array}$ \\
\hline mtDNA in & ression into L. gra & & & & \\
\hline ILS & $\begin{array}{l}L g-S L v v \\
L g-L v m \\
L g-L s \\
\text { SLvv-Lvm } \\
\text { SLvv-Ls } \\
L v m-L s \\
\text { Combined } \\
\text { (Fisher's method) }\end{array}$ & $\begin{array}{l}0.0000 \\
0.0139 \\
0.0208 \\
0.0069 \\
0.0139 \\
0.0396\end{array}$ & $\begin{array}{l}0.0049 \\
0.0059 \\
0.0059 \\
0.0039 \\
0.0049 \\
0.0069\end{array}$ & $\begin{array}{l}0.006 \\
0.120 \\
0.036 \\
0.164 \\
0.042 \\
0.022 \\
0.0001\end{array}$ & $\begin{array}{l}\mathrm{O}<\mathrm{E} \\
\mathrm{O}=\mathrm{E} \\
\mathrm{O}>\mathrm{E} \\
\mathrm{O}=\mathrm{E} \\
\mathrm{O}>\mathrm{E} \\
\mathrm{O}>\mathrm{E} \\
\text { data do not fit } \\
\text { scenario }\end{array}$ \\
\hline Hyb & $L g-S L v v$ & 0.0000 & 0.0020 & 0.180 & $\mathrm{O}=\mathrm{E}$ \\
\hline $\operatorname{Lg}-\mathrm{S} L v v$ & $\begin{array}{l}L g-L v m \\
L g-L s \\
\text { SLvv-Lvm } \\
\text { SLvv-Ls } \\
L v m-L s \\
\text { Combined } \\
\text { (Fisher's method) }\end{array}$ & $\begin{array}{l}0.0139 \\
0.0208 \\
0.0069 \\
0.0139 \\
0.0396\end{array}$ & $\begin{array}{l}0.0069 \\
0.0118 \\
0.0069 \\
0.0118 \\
0.0138\end{array}$ & $\begin{array}{l}0.086 \\
0.212 \\
0.832 \\
0.560 \\
0.080 \\
0.1152\end{array}$ & $\begin{array}{l}\mathrm{O}=\mathrm{E} \\
\mathrm{O}=\mathrm{E} \\
\mathrm{O}=\mathrm{E} \\
\mathrm{O}=\mathrm{E} \\
\mathrm{O}=\mathrm{E} \\
\text { data fit } \\
\text { scenario }\end{array}$ \\
\hline
\end{tabular}


Figure 1. Map with ranges of morphological subspecies (A). Delimitation of evolutionary lineages in the Lissotriton vulgaris species group in STRUCTURE (B). Pie charts show mean individual cluster membership coefficients. $L g-L$. graecus; $L k-L$. kosswigi; $L l-L$. lanzti; Lm - L. montandoni; Ls - L. schmidtleri; Lva - L. v. ampelensis; Lvm - L. v. meridionalis; NLvv - North L. v. vulgaris; SLvv - South L. v. vulgaris

Figure 2. Phylogenetic relationships among STRUCTURE-delimited groups of Lissotriton newts; most genetic groups correspond to morphologically defined subspecies (except for $L$. v. vulgaris that is split into northeastern and southwestern lineages and L. v. ampelensis which contains two morphologies; see text for details). (A) Majority-rule consensus tree based on 10 replicate analyses (Fig. S4) of 74 concatenated nuclear loci for a total of 36,918 bp; values designate the frequencies of clades found across replicates. Filled circles at nodes indicate congruence across concatenation, concordance and TreeMix analyses. (B) Majority-rule consensus of 50 primary concordance trees. Frequency of clades over all replicates (top number) and concordance factors shown as the mean number of loci (out of 70) supporting the clade $( \pm S D)$. (C) Maximum likelihood tree as inferred by Treemix based on 355 SNPs; horizontal branch lengths are proportional to the amount of genetic drift that has occurred in each lineage. (D) Inferred evolutionary relationships among newt groups by TreeMix with one (left), two (middle) and three (right) migration events. The migration arrows are coloured according to their weights; the weight is correlated with the ancestry fraction.

Figure 3. Top: pairwise $d_{\mathrm{xy}}$ distances among Lissotriton taxa. Bottom: proportion (in percent, left y-axis and solid circles) of shared haplotypes out of total number of haplotypes summed for each taxon pair across 74 markers; values above solid circles indicate the number of alleles shared by each taxon pair. Note that taxon pairs are in the same order on both charts. Lg-L. graecus; Lk - L. kosswigi; Ll - L. lanzti; Lm - L. montandoni; Ls - L. schmidtleri; 
Lva - L. v. ampelensis; Lvm - L. v. meridionalis; NLvv-North L. v. vulgaris; SLvv-South L.

883 v. vulgaris

884 Figure 4. Pie charts representing posterior distributions of Approximate Bayesian

885 Computation analyses in pairwise taxon comparisons (A), color coded according to

886 demographic models (inset in A). Lissotriton vulgaris group phylogeny showing well-

887 supported instances of post-divergence gene flow (green arrows) and their corresponding

888 posterior distributions from the ABC analyses (B).

889 Figure 5. Parameters of species trees under competing scenarios of incomplete lineage

890 sorting (ILS) and hybridization (HYB). Both $\theta$ and $\tau$ are measured as the expected number of mutations per site. 

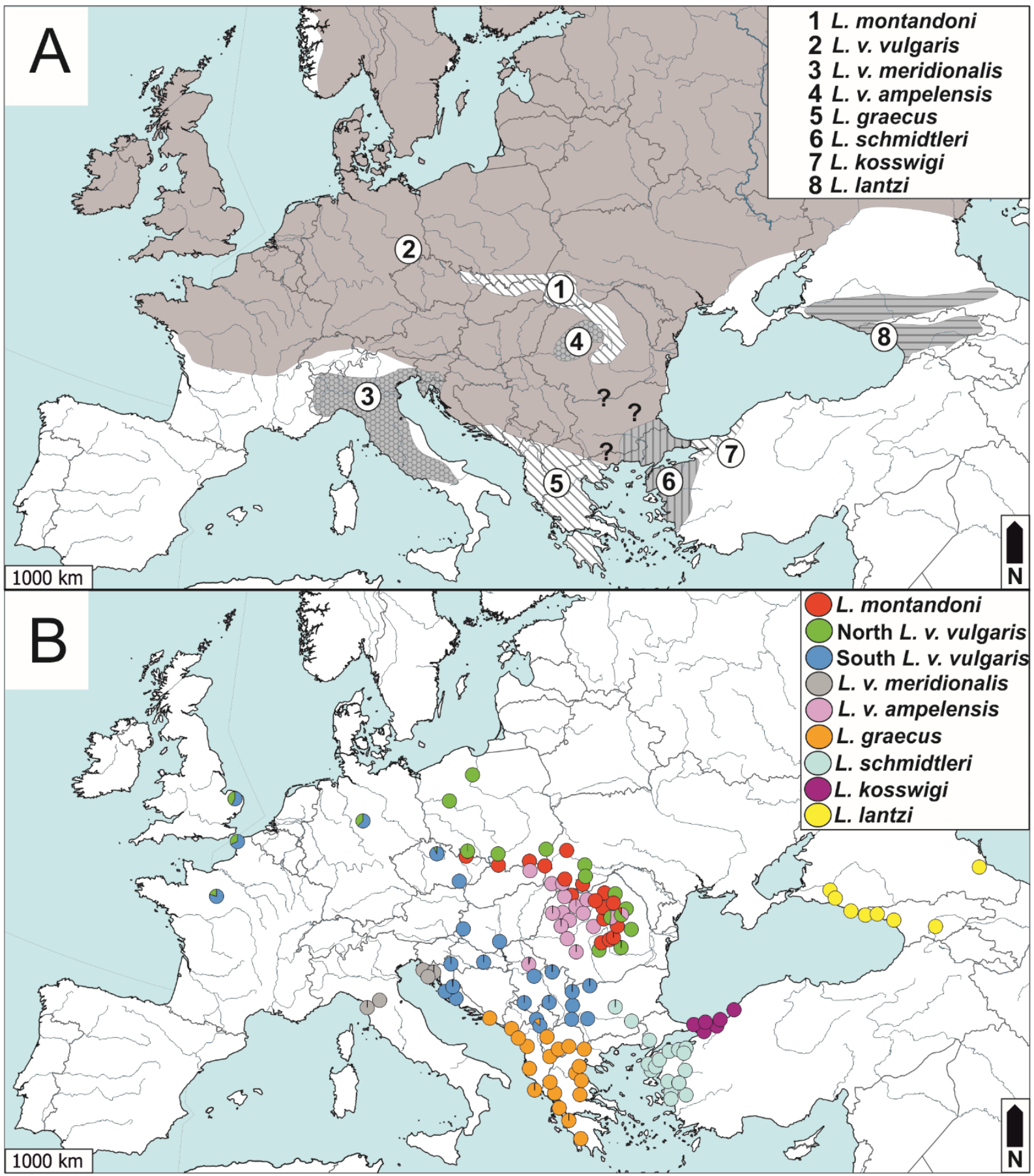

Fig. 1. 
bioRxiv preprint doi: https://doi.org/10.1101/095877; this version posted June 28 2017. The copyright holder for this preprint (which was not certified by peer review) is the author/funder, who has granted bioRxiv a license to display the preprint in perpetuity. It is mage 4 available under aCC-BY-NC-ND 4.0 International license.

(A)

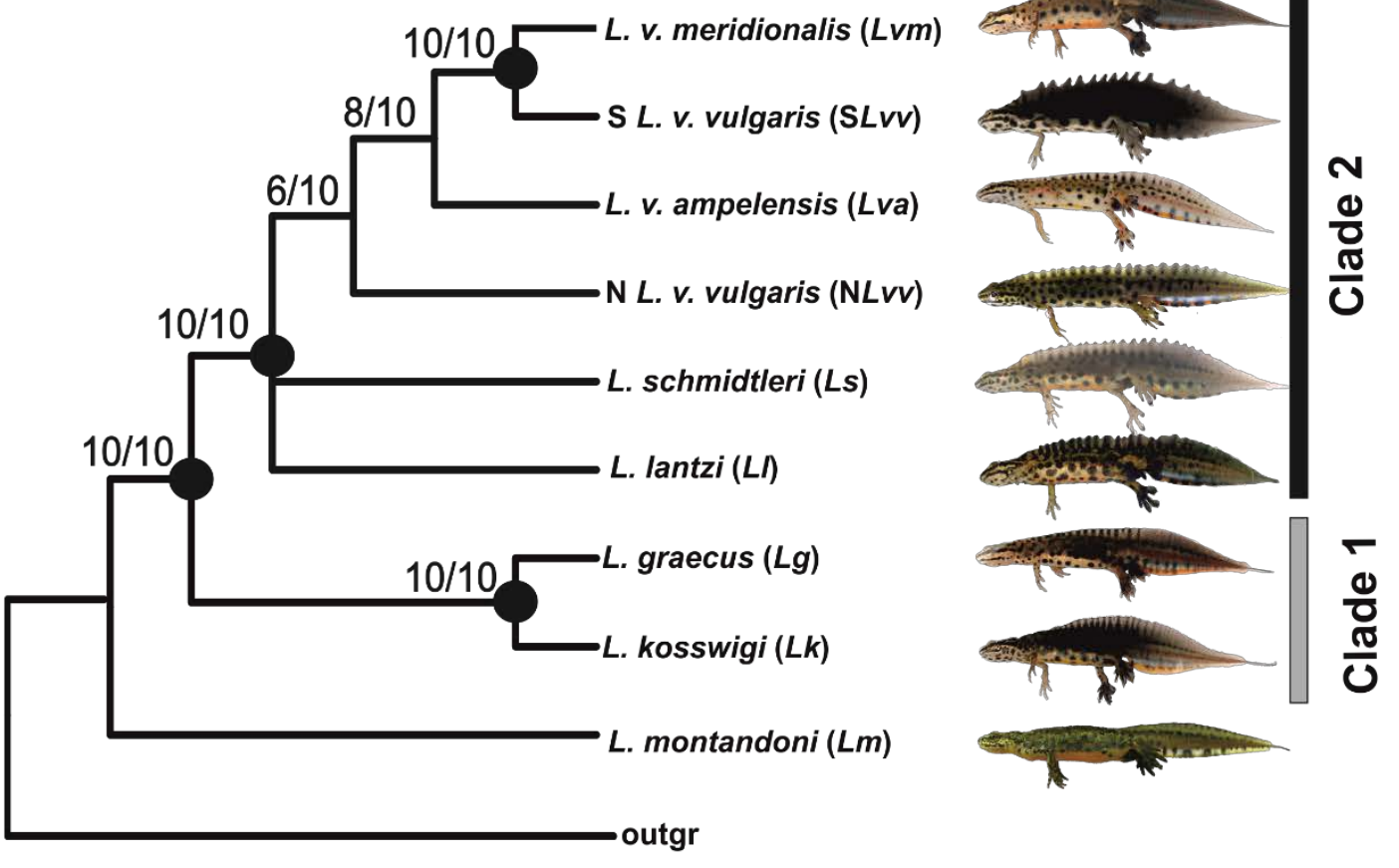

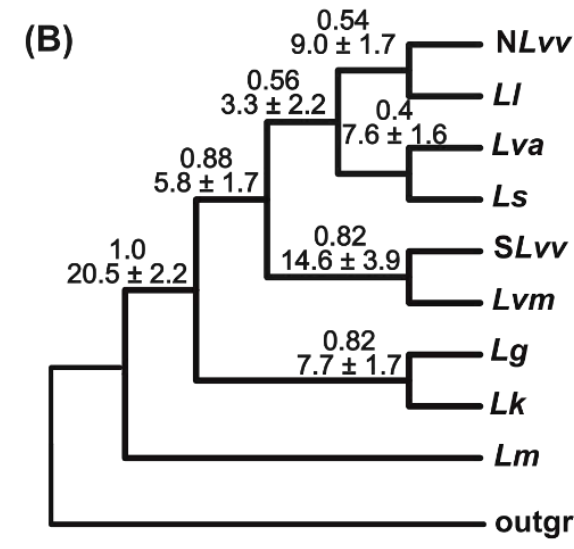

(D)
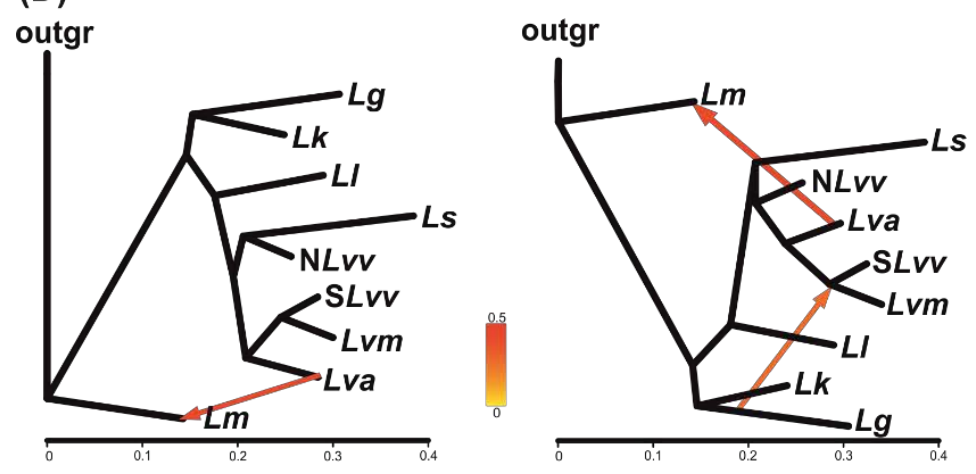

(C)
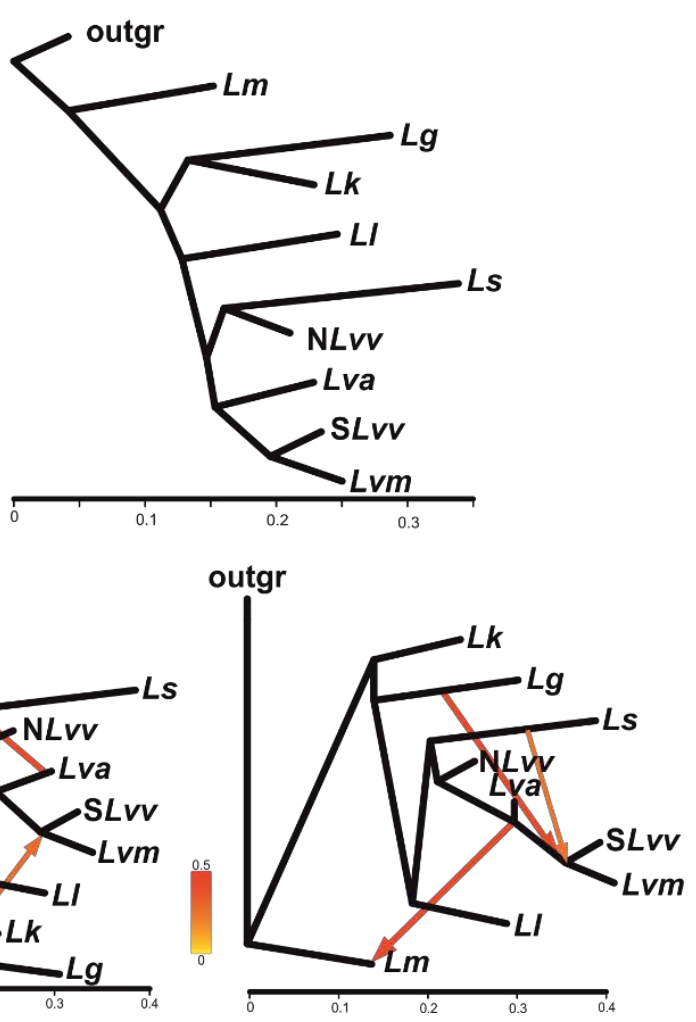

Fig. 2. 
bioRxiv preprint doi: https://doi.org/10 1101/095877; this version posted June 28, 2017. The copyright holder for this preprint (which was not certified by peer review) is the author/funder, who has granted bioRxiv a license to display the preprint in perpetuity. It is maple available under aCC-BY-NC-ND 4.0 International license.

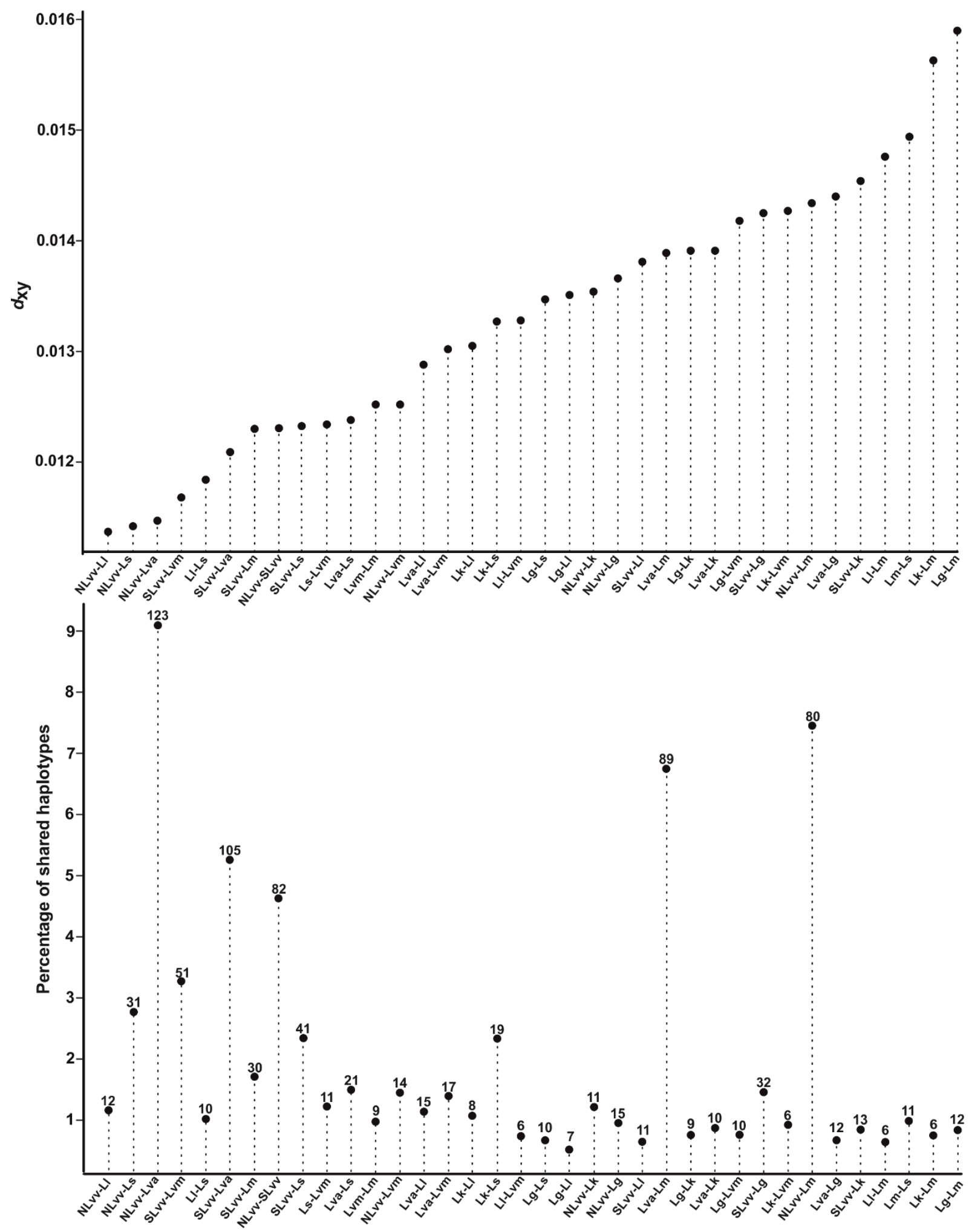

Fig. 3. 
(A)

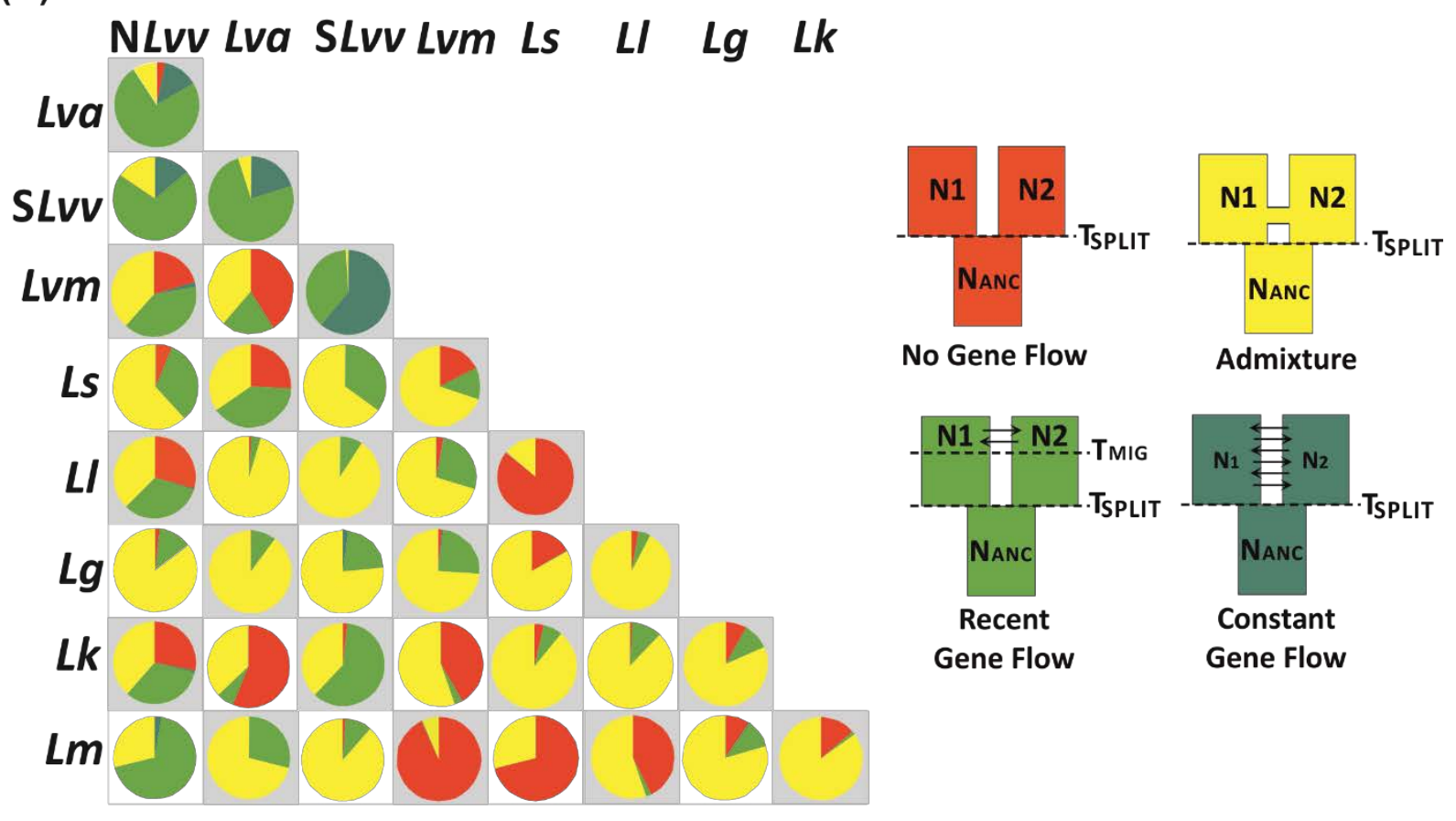

(B)

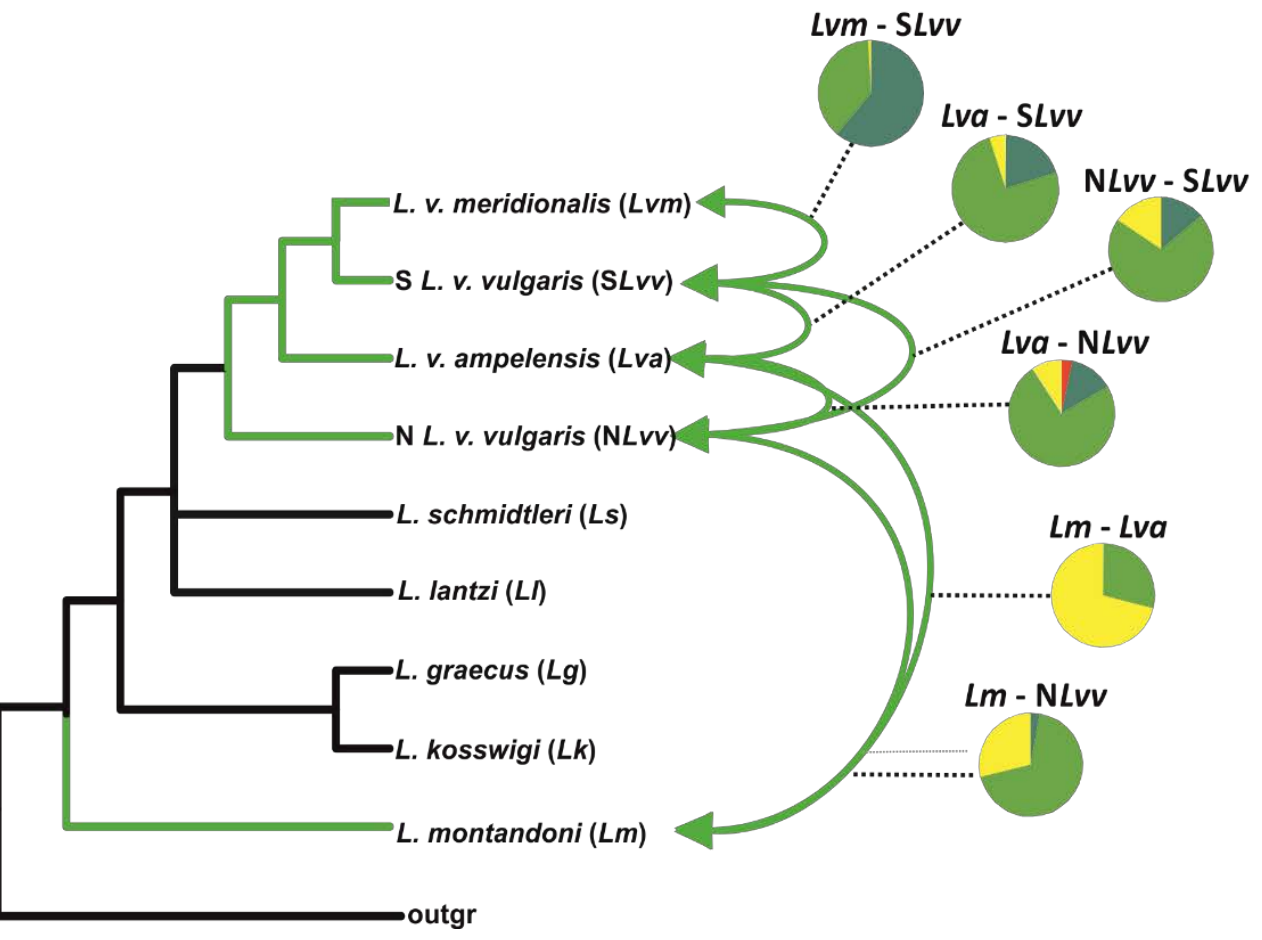

Fig. 4 
bioRxiv preprint doi: https://doi.org/10.1101/095877; this version posted June 28, 2017. The copyright holder for this preprint (which was not certified by peer review) is the author/funder, who has granted bioRxiv a license to display the preprint in perpetuity. It is mapte available under aCC-BY-NC-ND 4.0 International license.

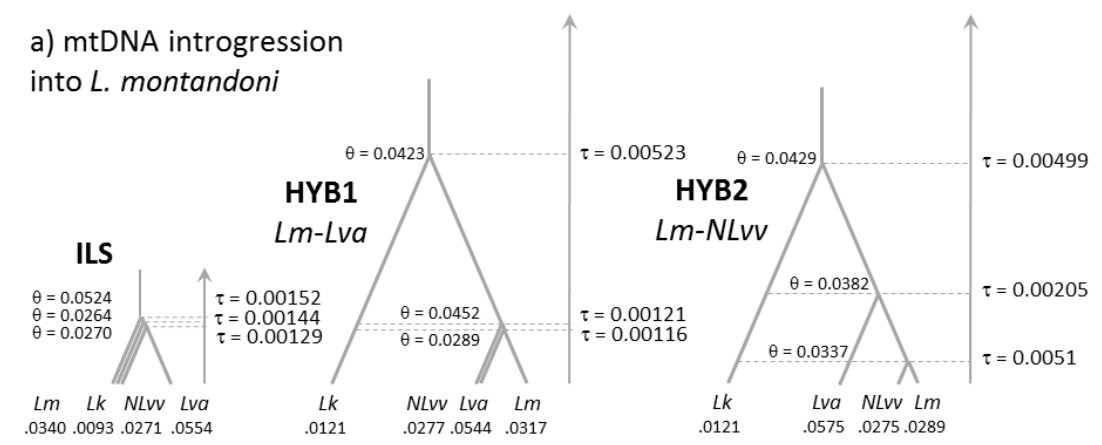

\section{b) mtDNA introgression into $L$. graecus}




\section{SUPPORTING INFORMATION}

905

906

907

908

909

910

911

912

913

914

915

916

917

918

919

920

921

922

923

924

925

Extended Methods: Validation of OTUs in BPP, phylogenetic analysis using BUCKy, and ABC analyses.

Table S1. A list of newt specimens with individual ID numbers, morphological species designation, geographical provenance and estimated proportion of genes in STRUCTUREdefined genetic clusters (c1-c9) representative of the species delimitation proposed in this study.

Table S2. Datasets used for species delimitation and phylogenetic reconstruction.

Table S3. Summary statistics for pairwise comparisons of Lissotriton taxa used in Approximate Bayesian Computation analyses.

Table S4. Summary of the nucleotide variation in 74 nuclear markers (mostly 3' UTR regions) in Lissotriton vulgaris (including all lineages delimited herein) and L. montandoni.

Table S5. Summary of STRUCTURE results for $K=7-12$, iterated 10 times each for a total of 60 separate analyses.

Table S6. Pairwise matrix of $d_{\mathrm{xy}}$ values calculated for newt OTUs.

Table S7. Results of Approximate Bayesian Computation analyses under four demographic models: no gene flow (NGF), constant gene flow after divergence (CGF), recent (<200 kya) gene flow (RGF), and instantaneous admixture after divergence (ADM).

Table S8. Power analysis for Approximate Bayesian Analyses.

Table S9. Prior and posterior distributions for best model in pairwise taxon comparisons in Lissotriton newts from ABC analyses. 
926 Figure S1. Relationships among major mtDNA lineages (denoted by capital letters) in

927 Lissotriton, modified from Pabijan et al. (2015).

928 Figure S2. Estimated Ln probability of the data for a given $K$, from STRUCTURE

929 HARVESTER; ten replicate analyses were run for each $K$.

930 Figure S3. Additional substructure found within South L. v. vulgaris and L .graecus.

931 Figure S4. Consensus trees from 10 replicates of concatenated analyses in MrBayes.

932 Figure S5. Variation in concordance factors (expressed as the number of genes supporting a

933 particular clade) for main clades found in 50 replicate BUCKy analyses.

934 Figure S6. Scaled residual fit from the TreeMix analysis based on the maximum likelihood 935 tree in Fig. 2C (no migration edges). 